\title{
PROPRIEDADES GEOQUÍMICAS E PROVENIÊNCIA DE ROCHAS METASSEDIMENTARES DETRÍTICAS ARQUEANAS DOS GREENSTONE BELTS DE CRIXÁS E GUARINOS, GOIÁS
}

\author{
HARDY JOST ${ }^{*}$, SUZI MARIA DE CÓRDOBA HUFF THEODORO**; ANA MARIA GRACIANO FIGUEIREDO' \\ \& GERALDO RESENDE BOAVENTURA*
}

\begin{abstract}
GEOCHEMICAL PROPERTIES AND PROVENANCE OF DETRITAL ARCHAEAN METASEDIMENTARY ROCKS OF THE CRIXAS AND GUARINOS GREENSTONE BELTS, GOIÁS Metasedimentary rocks derived from debited clay-rich protoliths occur only in the upper stratigraphic sections of the Crixás and Guarinos greenstone belts, Central Brazil. They consist of carbonaceous schist ( $\pm 100 \mathrm{~m}$ thick), overlain by $300 \mathrm{~m}$ thick distal metaturbidites (fine-grained clayey metarenite, metasiltite and metashale). In $85 \%$ of the samples, the $\mathrm{SiO}_{2} /\left(\mathrm{Al}_{2} \mathrm{O}_{3}+\mathrm{CaO}+\mathrm{Na}_{2} \mathrm{O}+\mathrm{K}_{2} \mathrm{O}\right)$ ratio is similar to post-Archaean detrital sedimentary rocks suggesting that their source-area underwent moderate weathering. The average abundances of major, minor and trace elements of carbonaceous schist and the metarenite/ metashale turbidite pair, suggest that no major compositional changes of their respective source-areas took place during sedimentation. Petrographic and geochemical data show that the metarenites and metasiltites derived from clay-rich protholits and in the average are geochemicaly consistent with the genetically related metashales. Major and minor oxides as well as trace elements vary consistently with an empirical detrital sedimentary maturity index $\left.\left(\mathrm{SiO}_{2} / \mathrm{SiO}_{2}+\mathrm{Al}_{2} \mathrm{O}_{3}\right) \times 100\right)$, and with the white mica/chlorite \pm biotite ratios and probably also respond to the composition of white mica and chlorite. The majority of samples have a $\Sigma$ REE compatible with other Archaean equivalent rocks and Phanerozoic quartz-poor to quartz-rich graywackes. Normalized to NASC, the carbonaceous schist, metashales and metarenites ( + metasiltites) derive two populations distinguished by their REE abundance. In contrast to post-Archaean equivalent rocks, the studied lithotypes are poorer in LREE, have positive $\mathrm{Eu}_{\mathrm{N}} / \mathrm{Eu}_{\mathrm{N}}{ }_{\mathrm{N}}$ anomalies and lack HREE fractionation. In the average, the composition of the studied rocks are richer in $\mathrm{Fe}_{2} \mathrm{O}_{3}{ }^{*}, \mathrm{CaO}, \mathrm{MgO}, \mathrm{MnO}, \mathrm{Cr}, \mathrm{Ni}, \mathrm{Co}, \mathrm{Sc}, \mathrm{V}$, and $\mathrm{Ba}$ as compared to port-archean rocks. The $\mathrm{La} / \mathrm{Sc} \mathrm{Sc} / \mathrm{La}, \mathrm{Th} / \mathrm{La}$ and $\mathrm{Cr} / \mathrm{Ti}$ ratios are higher and the $\mathrm{Zr} / \mathrm{Y}$ ratios are lower than post-Archaean rocks and lead to a bimodal provenance model. Modeling of the source-area shows that a geochemically anomalous horizon of Guarinos may be explained by a source-area with 1:1, while other samples by a 9:1 basalt:komatiite ratio, both with similar contribution of a tonalite/trondhjemite felsic component.
\end{abstract}

Keywords: geochemistry, provenance, detrital metasedimentary rocks, Archaean, Goiás

RESUMO Rochas metassedimentares derivadas de protólitos detríticos ricos em argilo-minerais ocorrem apenas nas porções estratigráficas superiores dos greenstone belts de Crixás e Guarinos, Goiás. Estas consistem de xistos carbonosos (espessura média de $100 \mathrm{~m}$ ), sotopostos a mais de $300 \mathrm{~m}$ de metaturbiditos distais (metarenitos finos argilosos, metasiltitos e metafolhelhos). Em $85 \%$ das amostras, a razão $\mathrm{SiO}_{2} /\left(\mathrm{Al}_{2} \mathrm{O}_{3}+\mathrm{CaO}+\mathrm{Na}_{2} \mathrm{O}+\mathrm{K}_{2} \mathrm{O}\right)$ é similar a de rochas sedimentares detríticas pós-arqueanas e sugere área-fonte sob intemperísmo moderado. A abundância média de elementos maiores, menores e traços de xistos carbonosos e do par rítmico metarenito/metafolhelho é semelhante, sugerindo que não houve uma modificação substancial da área-fonte durante a mudança de regime tectônico que controlou a sedimentação. Dados petrográficos e geoquímicos indicam que os protólitos dos metarenitos e metassiltitos, pares geneticamente associados dos metaturbiditos, eram ricos em argilo-minerais e mostram variações geoquímicas consistentes com o fracionamento de argilo-minerais durante a sedimentação. Variacões de elementos maiores, menores e traços são consistentes com um índice empírico de maturidade sedimentar detrítica $\left.\left(\mathrm{SiO}_{2} / \mathrm{SiO}_{2}+\mathrm{Al}_{2} \mathrm{O}_{3}\right) \times 100\right)$, e com as razões mica branca/cloríta \pm biotita e suas respectivas composições. A maioria das amostras possue um $\sum$ REE e assinaturas compatíveis com equivalentes arqueanas e grauvacas fanerozóicas pobres a ricas em quartzo e derivam duas populacõos distintas. Em média, as rochas estudadas são mais ricas em $\mathrm{Fe}_{2} \mathrm{O}_{3} *, \mathrm{CaO}, \mathrm{MgO}, \mathrm{MnO}, \mathrm{Cr}$, Ni, $\mathrm{Co}, \mathrm{Sc}, \mathrm{V}$ e Ba que as pós-arqueanas. As razões $\mathrm{La} / \mathrm{Sc}, \mathrm{Th} / \mathrm{La}$ e $\mathrm{Cr} / \mathrm{Ti}$ são maiores e $\mathrm{Zr} / Y$ menores que as rochas pós-arqueanas e conduzem a um modelo de proveniência bimodal, segundo o qual um horizonte anômalo de Guarinos pode ser explicado por uma razão basalto:komatiito de $1: 1 \mathrm{e}$ as demais amostras por uma razão 9:1, com variadas proporções de uma contribuição tonalítico/trondhjemítica, não diferindo, assim, do observado em rochas sedimentares neo-arqueanas de outras áreas continentais.

Palavras-chaves: geoquímica, proveniência, rochas metassedimentares detríticas, Arqueano, Goiás

INTRODUÇÃO A partir da década de 70 , as propriedades geoquímicas de rochas sedimentares antigas vêm sendo gradual e crescentemente empregadas para inferir a composição da crosta exposta e a natureza dos processos superficiais à época da deposição. No decurso das duas últimas décadas, passou-se a conhecer que as rochas sedimentares detríticas arqueanas apresentam significativas diferenças composicionais, comparativamente as suas equivalentes pósarqueanas. Estas diferenças são interpretadas como uma das múltiplas respostas à modificação do sistema manto/crosta ocorrida na transição do Neoarqueano ao Paleoproterozóico, transição esta caracterizada por um aumento significativo no volume de crosta continental. Assim, enquanto as rochas sedimentares arqueanas foram depositadas sob um regime de abundante vulcanismo máfico e ultramáfico, as pós-arqueanas resultaram da erosão de extensas áreas cratônicas de composição média granodiorítica (Taylor \& McLennan 1985).

A natureza geoquímica de rochas sedimentares, e equivalentes metamórficas, de todos os núcleos arqueanos preservados são, em geral, similares, como mostram as investigações realizadas, por exemplo, no Canadá (Feng \& Kerrich 1990, Camiré et al 1993, Mueller et al. 1994), África do Sul (Wronkiewicz \& Condie 1987), Austrália (Nancy \& Taylor 1976, Maas \& McCulloch 1991), Estados Unidos (Jenner et al. 1981,Gibb et al. 1986), e índia (Naqvi et al. 1988,Arora et al 1994). Na Plataforma Sulamericana, estes estudos são recentes e aparentemente se restringem à região de Crixás, em

* Instituto de Geociências, Universidade de Brasília, 70919-970, Brasília, DF - e-mail: hjost@tba.com.br

** Centro de Desenvolvimento Sustentável - CDS -Universidade de Brasília, SAS, Quadra 5, Bloco H, 2 Andar, 70070-914, Brasília, DF

*** Instituto de Pesquisas Energéticas e Nucleares - IPEN, Caixa Postal 11049,05422-970, São Paulo - e-mail: grafigue@ihO.ipen.br ou grafigue@baitaca.ipen.br 
Goiás (Magalhães 1991, Jost et al. 1993, Jost et al. 1995) e de Piumhi, Minas Gerais (Lima 1996).

Na região de Crixás, as rochas supracrustais ocorrem em três faixas sub-paralelas, com cerca de $40 \mathrm{~km}$ de comprimento e 7,5 km de largura média (Fig. 1), separadas por complexos granito-gnáissicos e denominadas, de oeste para leste, de Crixás, Guarinos e Pilar de Goiás. As três faixas possuem, em comum, unidades estratigráficas inferiores com rochas metavulcânicas e superiores de rochas metassedimentares. Apenas as faixas Crixás e Guarinos possuem, nas porções estratigráficas superiores, rochas metassedimentares autóctones derivadas de protólitos detríticos (Fig. 2). As unidades vulcânicas consistem de 400 a $600 \mathrm{~m}$ de espessura de metakomatiitos basais, seguidos de 400 a $500 \mathrm{~m}$ de metabasaltos toleiíticos, ambas com intercalações menores de formações ferríferas, metachert e formações manganesíferas. Ao término do vul-

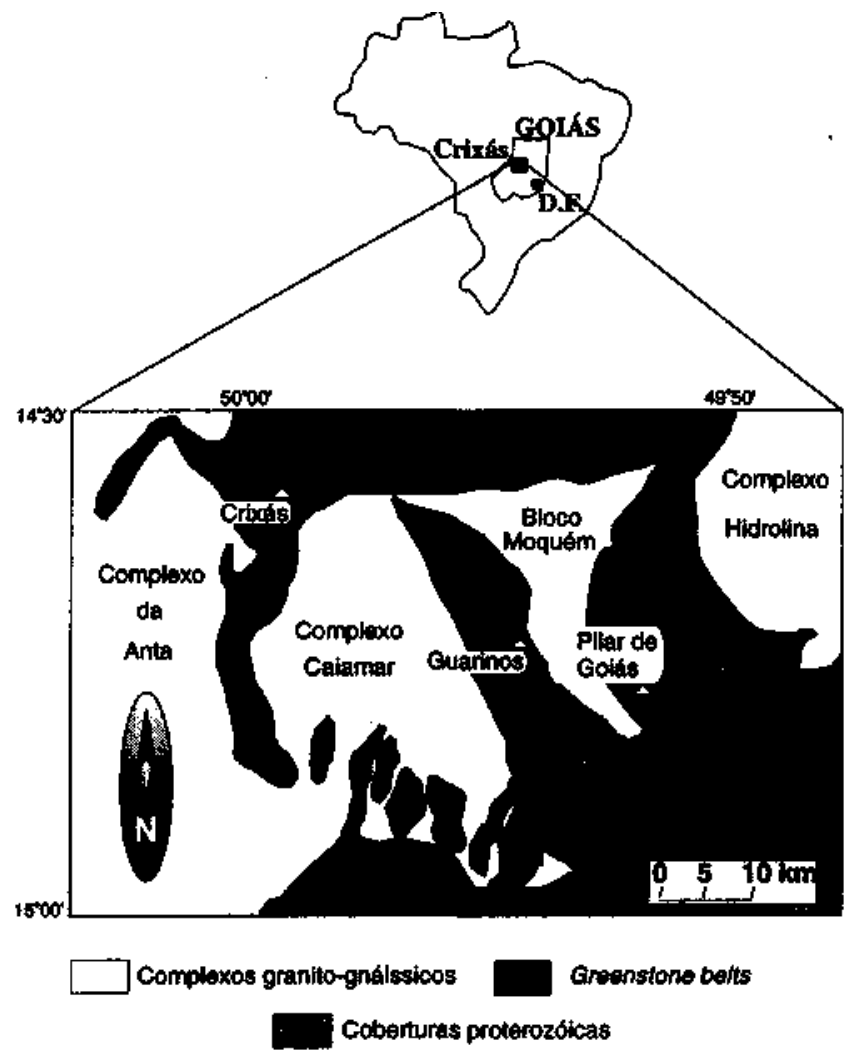

Figura 1 - Localização e esboço geológico da região arqueana de Crixás, Goiás (Modificado de Jost \& Oliveira 1991).

Figure 1 - Location and geologic sketch of the Crixás Archean region, Goiás (modified after Jost \& Oliveira 1991)

canismo básico toleiítico, ambas faixas evoluíram por sedimentação, com vulcanismo subordinado.

Em Crixás, a sedimentação ocorreu em dois estágios. $\mathrm{O}$ vulcanismo toleí́tico foi rápida e progressivamente substituído por um ambiente detrítico anóxico (Theodoro 1995), representada em cerca de $200 \mathrm{~m}$ de xistos carbonosos de origem orgânica (Fortes 1995). Na metade inferior, os xistos carbonosos apresentam intercalações de mármores com relíquias de oólitos e prováveis esteiras algálicas, indicativas de águas rasas e planícies de maré (Theodoro 1995, Theodoro \& Jost 1996), e, na superior, camadas métricas de xisto carbonoso com fragmentos de provável púmice, sugerindo vulcanismo félsico distai contemporâneo. Em Guarinos, cerca de $200 \mathrm{~m}$ de xistos carbonosos ingressam gradualmente ao final de deposição de cerca de $80 \mathrm{~m}$ de formações ferríferas com lentes de metaconglomerados e metafolhelhos basais (Resende 1994, Resende \& Jost 1994), depositados sobre uma superfície de discordância que expunha rochas metassedimentares detríticas lateralmente interdigitadas a metabasaltos. $\mathrm{O}$ ciclo sedimentar de ambas faixas encerra com uma espessa seqüência de metaturbiditos distais, em contato brusco com os xistos carbonosos sotopostos.

O presente artigo visa descrever, comparar e interpretar as principais características geoquímicas dos xistos carbonosos e metaturbiditos distais comuns a ambas as faixas, observar o comportamento de elementos imóveis devido à mudança de ambiente de deposição, interpretar a proveniência dos detritos sólidos dos protólitos destas rochas e compará-la com a de outros núcleos arqueanos mundiais.

MATERIAIS E MÉTODOS As amostras de xisto carbonoso e metaturbidito das porções estratigráficas estudadas provêm de 8 furos de sondagem da Mina III, em Crixás, e de uma seção estratigráfica com $340 \mathrm{~m}$ de espessura e algumas amostras de afloramentos da porção norte de Guarinos. A descrição petrográfica de aproximadamente 150 lâminas delgadas determinou a seleção de 81 amostras isentas de alterações hidrotermal e superficial para análise química.

A determinação das proporções de óxidos de elementos maiores e menores, e de elementos traços foi realizada no Laboratório de Geoquímica da Universidade de Brasília (LAGEq/UnB). $\mathrm{FeO}$ foi determinado por volumetria, $\mathrm{K}_{2} \mathrm{O}$ e $\mathrm{Na}_{2} \mathrm{O}$ por Espectrometria de Emissão em Chamas, Perda ao Fogo (P.F.) por gravimetria e os demais óxidos, assim como $\mathrm{Cu}, \mathrm{Cr}, \mathrm{Ni}, \mathrm{Co}, \mathrm{V}, \mathrm{Ba}, \mathrm{Sr}, \mathrm{Zr}$ e $\mathrm{Y}$ por Espectrometria de Emissão em Plasma Indutivamente Acoplado (ICP). Dentre estas foram selecionadas 28 amostras por tipo de rocha (metarenito, metafolhelho e xisto carbonoso) para análise de ETR, Sc, U, Th e Hf por ativação neutrônica (INAA) no Instituto de Pesquisas Energéticas e Nucleares (IPEN-CNEN) de São Paulo. Outras 5 amostras foram analisadas por ICP no laboratório da GEOSOL - Geologia e Sondagens Limitada, em Belo Horizonte.

Os resultados analíticos, agrupados por litótipo e por faixa, constam das Tabelas I, II e III. A Tabela IV contém os dados de um horizonte com cerca de $30 \mathrm{~m}$ de espessura que inicia a $40 \mathrm{~m}$ da base dos metaturbiditos de Guarinos (ver figura 2). O horizonte consiste de uma alternância de camadas métricas de metaturbidito, xistos carbonoso e derrames de basaltos komatiíticos, denominado por Jost et al. (1995) de Horizonte Anômalo. As Tabelas V e VI contêm os dados de Elementos Terras Raras (ETR) das rochas analisadas.

PETROGRAFIA As rochas metassedimentares estudadas foram originalmente divididas em quatro grupos, de acordo com as proporções de minerais micáceos metamórficos e matéria carbonosa e compreenderam metarenitos, metassiltitos, metafolhelhos e xistos carbonosos. Posteriormente, metarenitos e metasiltitos foram reunidos em um único grupo, pois, apesar de suas diferenças texturais, estes não diferem nas proporções de minerais micáceos e composição química. Em vista disto, nos parágrafos seguintes, o termo metarenito significará, indistintamente, metarenitos e metassiltitos.

Metarenitos, metasiltitos e metafolhelhos são litótipos associados, pois formam os ritmos individuais, granoclassificados, dos metaturbiditos. Essas rochas são, em geral, laminadas a estratificadas e possuem relíquias de estruturas sedimentares, tais como laminação planoparalela e cruzada, de corte-e-preenchimento, em chama e laminação rítmica com granoclassificação decrescente.

As associações de minerais metamórficos destas rochas indicam condições da fácies xisto verde, entre a zona da biotita e da granada. Não foram observados minerais tais como 

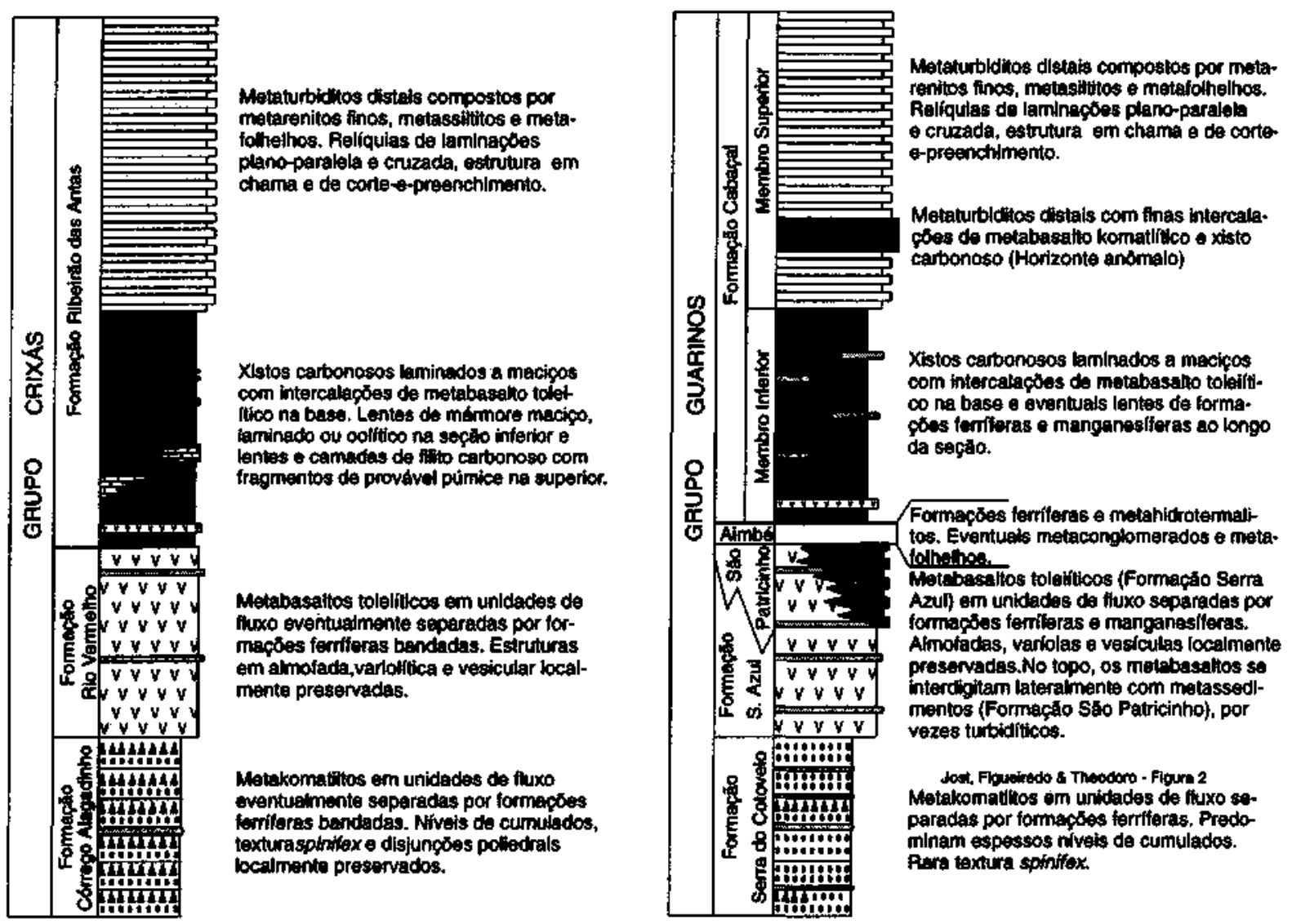

Figura 2 - Sintese da estratigrafia dos greenstone belts de Crixás e Guarinos, Goiás. Compilado de Jost \& Oliveira (1991), Resende (1994), Resende (1995) e Theodoro (1995).

Figure 2 - Stratigraphic synthesis of the Crixás and Guarinos greenstone belts, Goiás. Compiled from Jost \& Oliveira (1991), Resende (1994), Resende (1995), and Theodoro (1995).

Tabela I - Composição química de xistos carbonosos dos greenstone belts de Crixás e Guarinos. Óxidos em \% de peso, IAQ e IMAT em \% e elementos traço em ppm.

Table I - Chemical composition of carbonaceous schists of the Crixás and Guarinos greenstone belts. Oxides in weight \%, IAQ (Chemical Alteration Index) and IMAT in \% and trace elements in ppm.

\begin{tabular}{|c|c|c|c|c|c|c|c|c|c|c|c|c|c|c|}
\hline & \multicolumn{8}{|c|}{ chist: } & \multicolumn{6}{|c|}{ Goptinas } \\
\hline Ammotro & 1 & 2 & 11 & con-104 & 28 & 30 & 4 & 25 & 44,50 & 45,50 & 0,55 & 14,70 & SED-30 & $92-111-161$ \\
\hline $\mathrm{SiO}_{2}$ & 50.10 & 61,49 & 62,78 & 53,90 & 82,4 & $62 ; 0$ & 59,60 & 51,20 & 57,12 & 56,20 & 49,93 & $46,2 \mathrm{~L}$ & 63,80 & 63,11 \\
\hline $\mathrm{THO}_{2}$ & 1,00 & 093 & 0.61 & 1,94 & 0,19 & 0,67 & 0,79 & 0,79 & 0,65 & 0,66 & 1,10 & 0,76 & 0,95 & 1,12 \\
\hline NhOn & 13.25 & 15.46 & t.9. & 22,74 & 8.49 & 16,95 & 15,90 & 13,19 & 12.75 & 11,60 & 12,06 & 15,78 & 19,20 & 13,75 \\
\hline $\mathrm{F} \rightarrow \mathrm{O}^{\prime \prime *}$ & 12,43 & 10,44 & 9,49 & 7,53 & 2,70 & 6,67 & 28 & 11,06 & 8,07 & 11,97 & 15,26 & 19,07 & 2.39 & 7,06 \\
\hline $\mathrm{MnO}$ & 0,41 & 0,07 & 0,16 & nol & 0,05 & $0.0 \mathrm{~L}$ & 0.11 & 0,15 & 0,04 & 0,10 & 0,57 & 0.20 & 0,07 & 0,69 \\
\hline $\mathrm{HgO}$ & 5,62 & 4,16 & 3,99 & 0,72 & 2,02 & 2,79 & 3,01 & 5,54 & 3,64 & 2,59 & 597 & 8,97 & 0,37 & 3,58 \\
\hline $\mathrm{CuO}$ & 6,60 & 0,84 & 4,18 & 0,66 & 0,46 & 1,38 & 2,29 & 4,37 & 0,34 & 0.35 & 1.13 & 0,57 & 0.27 & 0.09 \\
\hline $\mathrm{NmO}$ & 1,40 & 1,59 & 0,59 & 7,66 & 0,77 & 1,98 & 2,40 & 0,73 & 0,35 & 0,59 & 0,34 & 0.5B & 0.00 & 0.46 \\
\hline $\mathbf{k}=0$ & 2,12 & 2.67 & 2.10 & 2.98 & 1.35 & 2,82 & $1 \pi$ & 2,33 & 2,47 & 3,41 & 3,96 & 2.27 & 0,00 & 4,41 \\
\hline $\mathrm{P} \neq \mathrm{O}$ & 0,12 & 0,22 & 0,00 & 0,09 & 0,12 & 0.07 & 0.21 & 0.21 & 0,07 & 0.04 & 0,03 & 0.14 & 0,03 & 0,0 \\
\hline PF & 7,47 & 2,14 & 7,15 & 1.59 & 2,50 & 4,45 & 4,91 & 9.37 & $(4,32$ & 12,47 & 10,84 & 4,9 & 12,77 & 5,98 \\
\hline TOTAL & 99,98 & 100,01 & 99,97 & 10002 & 1019,05 & 999 & 99.87 & 98,97 & 99.82 & 99,88 & 99,51 & 9964 & 99,85 & 100.28 \\
\hline IAQ & 68,44 & 78,87 & 66,13 & 74,52 & 81,17 & $7 \pi 77$ & 78.5 & 72.51 & 82,62 & 75,8 & 72,96 & 85,09 & 98,61 & 75,76 \\
\hline twar & 79,0108 & 79,90 & 95,76 & 70,32 & 90,65 & 75,32 & 72,94 & 79,51 & 81.75 & 8399 & 80,54 & 74,54 & 76.86 & 82,11 \\
\hline $\mathrm{Cr}$ & 199 & $1, \$ 0$ & 123 & 320 & 146 & 150 & 166 & 186 & 126 & 101 & 2008 & 149 & 200 & 206 \\
\hline Ni & 150 & I6A & 269 & $20+7$ & 150 & (8) & 16 아 & 130 & 192 & 424 & 276 & 236 & L 10 & 266 \\
\hline $\mathrm{Ca}$ & 121 & 100 & 229 & 212 & 102 & 195 & 200 & JtI & 221 & 200 & 183 & 212 & 210 & 125 \\
\hline se & & 14 & & & & & & & 15 & 16 & 25 & 26 & & \\
\hline$v$ & 26 & 136 & 106 & 339 & 74 & t & 132 & 141 & 112 & 178 & 220 & 130 & 203 & 202 \\
\hline Ba & 4245 & 662 & 912 & 2015 & $10 \%$ & 2049 & 100 & $\mathbf{8} 12$ & 759 & 1343 & 975 & 504 & 1489 & I3GS \\
\hline $\mathrm{sr}$ & 165 & 79 & 27 & 117 & 134 & gI & 182 & 4 & 61 & 61 & 31 & 17 & 4 & 19 \\
\hline HI & & 5,3 & & & & & & & 2,6 & 2,44 & 3,90 & 2,10 & & \\
\hline $\mathbf{z}$ & 42 & 159 & 56 & 60 & 127 & ग & 90 & 9] & 96 & 30 & 26 & 153 & 98 & 84 \\
\hline $\mathbf{Y}$ & 19 & 22 & 21 & 10 & 17 & 6 & 26 & 14 & 24 & $n$ & 26 & 77 & 37 & 12 \\
\hline Th & & 6,10 & & & & & & & 9,4 & 8.6 & 10,30 & 10,09 & & \\
\hline U & & 2,10 & & & & & & & 5,008 & 9 & 1,51 & 590 & & \\
\hline
\end{tabular}


Tabela II - Composição química de metafolhelhos de metaturbiditos dos greenstone belts de Crixás e Guarinos. Óxidos em \% de peso,IAQ e IMATem \% e elementos traço em ppm.

Table II - Chemical composition of metashales of metaturbidites of the Crixás and Guarinos greenstone belts. Oxides in weight \%, IAQ and IMAT in \%, and trace elements in ppm.

\begin{tabular}{|c|c|c|c|c|c|c|c|c|}
\hline \multirow[b]{2}{*}{ Amostrin } & \multirow{2}{*}{$\frac{\text { Cinx/s }}{27}$} & \multicolumn{7}{|c|}{ Guarions } \\
\hline & & 30,0 & 34,40 & 40,00 & 103,85 & 295 & 300 & $92-11-190$ \\
\hline $\mathrm{SiO}_{2}$ & $\$ 4,91$ & 58,51 & 61,50 & $\$ 6,77$ & 58.50 & 58.20 & 51,80 & 59.71 \\
\hline $\mathrm{TiO}_{2}$ & 1,04 & 0,78 & 0,67 & 0.74 & 0.80 & 0,83 & 1,11 & 0,85 \\
\hline $\mathrm{Al}_{2} \mathrm{O}_{3}$ & 19,42 & 19.17 & 18,50 & 20,61 & 19,64 & 17,69 & 18,97 & 16,33 \\
\hline $\mathrm{F} e_{2} \mathrm{O}_{3}=$ & 9,35 & 6,67 & 7,04 & 9,76 & 7,55 & 9,47 & 11,16 & 10,92 \\
\hline MnO & 0,05 & 0.10 & 0,09 & 0,12 & 0,12 & 0,05 & 0.14 & 0,03 \\
\hline $\mathrm{MgO}$ & 4,69 & 2,33 & 2,27 & 2,99 & 2,47 & 3,48 & 4,23 & 3,31 \\
\hline $\mathrm{CEO}_{\mathrm{O}}$ & 0,72 & 1.53 & 0.78 & 0.75 & 0,87 & 2,35 & 3,21 & 0.16 \\
\hline $\mathrm{N}_{23} \mathrm{O}$ & 0.75 & 1,21 & 1,23 & 0,98 & 1,05 & 2.04 & 3,40 & 0,51 \\
\hline $\mathrm{K}_{2} \mathrm{O}$ & 4,32 & 2,81 & 3,00 & 3.03 & 3,28 & 3,62 & 3,42 & 5,32 \\
\hline $\mathrm{Br}_{3}$ & 0,29 & 0,17 & 0,15 & 0,14 & 0.13 & 0,23 & 0,38 & 0,06 \\
\hline PF, 4,45 & 5,60 & 4,98 & 4,12 & 5,38 & 2,86 & 2,98 & 3,40 & \\
\hline Total & 99.99 & 99,80 & 100,21 & 100,01 & 99,79 & 99,93 & 100,80 & 100,60 \\
\hline IAO & 80.03 & 82,12 & 82,41 & 84,40 & 82,56 & 75,05 & 73,06 & 75,45 \\
\hline MAT & 73,87 & 77,68 & $\$ 0,00$ & 73,36 & 74,86 & 76,70 & 73,19 & 78,52 \\
\hline $\mathrm{Cr}$ & 250 & 169 & 163 & 19] & 187 & 177 & 320 & 179 \\
\hline Ní & 180 & 150 & 200 & $|s|$ & 140 & 180 & 180 & 132 \\
\hline $\mathrm{Co}_{0}$ & 100 & 210 & 200 & 208 & 212 & 119 & 120 & 103 \\
\hline sc & & & & & & 23 & 23 & \\
\hline$v$ & 139 & 118 & III & 134 & 124 & 140 & 151 & 139 \\
\hline $\mathrm{Ba}$ & 936 & 930 & 910 & 980 & 1120 & 1000 & 1300 & 900 \\
\hline $\mathrm{sr}$ & 49 & 212 & 0 & 220 & 182 & 252 & 405 & 26 \\
\hline Hf & & & & & & 3,10 & 4,49 & \\
\hline $\mathbf{z x}$ & 141 & 57 & 101 & 94 & 126 & 105 & $9 \mathrm{t}$ & 94 \\
\hline $\mathrm{Y}$ & 23 & 14 & 13 & 22 & 19 & 20 & 24 & 31 \\
\hline Th & & & & & & 3,70 & 4,10 & \\
\hline $\mathrm{U}$ & & & & & & 1,14 & 0,89 & \\
\hline
\end{tabular}

estaurolita, típicos de metamorfismo de pelitos na fácies anfibolito inferior.

Os metarenitos são finos, cinza escuros a branco quando não intemperizados, amarelo quando alterados. Os metassiltitos se distinguem dos metarenitos apenas pela granulação menor. Ao microscópio, ambos possuem textura granoblástica a lepidoblástica, localmente porfiroblástica e são, respectivamente, finos a muito finos. Os constituintes maiores são quartzo (40-60\%), sericita (30-50\%) e clorita e/ou biotita (10-15\%), com granada subordinada. Minerais opacos, plagioclásio, feldspato potássico, zircão e apatita são raros. Os minerais opacos dos metarenitos são intersticiais ao quartzo e consistem de magnetita e ilmenita, ao passo que nos metasiltitos o opaco é hematita e intercrescida com clorita e/ou biotita, sugerindo que os primeiros são parte da população de minerais densos, enquanto a hematita é metamórfica. As proporções de sericita, biotita e clorita dessas rochas sugerem que os protólitos foram arenitos e siltitos argilosos.

Os metafolhelhos acompanham os metarenitos e metasiltitos em pares gradacionais. São rochas escuras que, em lâmina delgada, exibem textura lepidoblástica muito fina. Os constituintes principais compreendem sericita e/ou clorita \pm biotita, em proporções geralmente superiores a 80\%. Quartzo e, localmente, granada são subordinados. Minerais opacos são raros.

Os xistos carbonosos são pretos, pulverulentos, e finamente laminados. Ao microscópio, estes xistos possuem textura e composição mineral idênticas aos metafolhelhos, exceto pela presença de matéria carbonosa e pirita. A matéria carbonosa ocorre desde tracos, como inclusões microscópicas nos demais minerais, até filmes e lâminas com até $10 \%$ desta. A análise de concentrados de material carbonoso por difratometria de raios-x mostram que este é de baixa cristalinidade, inferior a da grafita (Theodoro 1995) e a composição isotópica de $\mathrm{C}$ e $\mathrm{O}$ sugerem uma origem orgânica (Fortes \& Takaki
1992). Em vista disto, interpretamos os xistos carbonosos como derivados de protólitos de ambiente anóxico com expressiva contribuição de prováveis ciano-bactérias.

GEOQUÍMICA Estimativa do Grau de Intemperismo A maioria dos estudos sobre intemperismo químico trata apenas das propriedades texturais e composicionais dos perfis de alteração. Uma tentativa de suportar, quantitativamente, uma comparação entre a composição de perfis de alteração e a de rochas sedimentares detríticas ricas em argilo-minerais foi investigada por Nesbitt \& Young $(1982,1984)$ e Cox et al. (1995). Os autores sugerem que o grau de intemperismo de áreas-fonte de sedimentos pode ser empiricamente estimado por um índice de Alteração Química (IAQ), dado por:

$$
\mathrm{IAQ}=\left[\mathrm{Al}_{2} \mathrm{O}_{3} /\left(\mathrm{Al}_{2} \mathrm{O}_{3}+\mathrm{Na}_{2} \mathrm{O}+\mathrm{K}_{2} \mathrm{O}+\mathrm{CaO}\right)\right] \times 100
$$

onde os óxidos são expressos em proporções moleculares e as de $\mathrm{CaO}$ incluem apenas as de silicatos, excluídas as de carbonato e apatita. Os feldspatos (ortoclásio, albita, anortita) possuem um IAQ $=40$ sugestivo de intemperismo ausente. No outro extremo, a caolinita, gibsita e clorita possuem um IAQ $=100$ e acomoda argilas residuais de intemperismo extremo. Outros produtos de intemperismo constam da figura 3 , juntamente com um histograma de freqüência do IAQ das amostras analisadas. O histograma não discrimina os três litótipos estudados.

Cerca de $85 \%$ das amostras estudadas possuem um IAQ superior a 70, compatível com intemperismo essencialmente químico. As demais (15\%) possuem um IAQ situado entre 40 e 70, onde se situam produtos sedimentares resultantes de intemperismo físico dominante. Petrograficamente, este grupo de amostras consiste de arenitos com feldspatos detríticos, ausentes no grupo dominante. 
Tabela III - Composição química de metafolhelhos de metaturbiditos dos greenstone belts de Crixás e Guarinos. Óxidos em \% de peso, IAQ e IMAT em\% e elementos traço em ppm.

Table III - Chemical composition of metarenites of metaturbidites of the Crixás and Guarinos greenstone belts. Oxides in weight \%, IAQ and IMAT in \%, and trace elements in ppm.

\begin{tabular}{|c|c|c|c|c|c|c|c|c|c|}
\hline & \multicolumn{9}{|c|}{ Crixkit } \\
\hline Ampasta & 3 & 12 & 16 & 19 & 20 & 26 & 34 & 39 & 43 \\
\hline $\mathrm{SHO}_{2}$ & 61,60 & 58,80 & 63.40 & 46,95 & 65.10 & 52,60 & 59,98 & 61,30 & 47,26 \\
\hline $\mathbf{T i O}$ & 0.97 & 1,06 & 0,99 & 1.29 & nst & 1,18 & 0.79 & 0.70 & 1,62 \\
\hline AbOY & 15,02 & 10.76 & 15.69 & 1896 & 15,53 & 17.51 & 15.98 & 15,92 & 20,41 \\
\hline $\mathrm{Fe}_{4} \mathrm{O}_{4}^{*}$ & 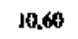 & 14.74 & 7,60 & 18.56 & 7,35 & 14,65 & 7.47 & $\mathbf{8 , 3 3}$ & 19,62 \\
\hline Mino & 0,13 & 0.06 & 0,07 & $0,0 \mathrm{~B}$ & 0,07 & 0,09 & 0,05 & 0,05 & 0,09 \\
\hline MgO & 4,00 & 3,04 & 3,30 & 7,12 & 3,22 & 3,58 & 3,61 & 3,69 & 2,54 \\
\hline $\cos$ & 1.80 & 5.01 & 1,97 & 0.37 & 1,39 & 1.98 & 1,41 & 0.93 & 2,49 \\
\hline $\mathrm{N}_{27} \mathrm{O}$ & 2.42 & 0,95 & 3.23 & 0.57 & 2,76 & 0,82 & 1,89 & 1.76 & 0,75 \\
\hline $\mathrm{K}_{2} \mathrm{O}$ & 252 & 1,06 & 1,83 & 241 & 2.50 & 2,4 & 3.58 & 2,42 & 3,35 \\
\hline $\mathrm{PtO}_{3}$ & 0,18 & 0.17 & 1,20 & 0,11 & 0,09 & 0,15 & 0,20 & 0,13 & 0,05 \\
\hline $\mathbf{P F}$ & $0, n$ & 4,34 & 1,90 & 3,57 & 1,18 & 5,01 & 5,12 & 4,92 & 1,80 \\
\hline Totrl & 100,01 & 99,49 & 99,98 & 99,99 & 100,00 & 100,01 & 99,98 & 99,99 & 100,00 \\
\hline IAO & 75.82 & 7138 & 76,9 & 67.22 & 76,34 & 82.00 & 75,21 & 5058 & 80.57 \\
\hline MAF & 95.76 & $\mathrm{BA}^{3} 3$ & 80,16 & 68,13 & 80,73 & 75,02 & 80,17 & 79.48 & 60,83 \\
\hline $\mathrm{Cr}_{\mathrm{r}}$ & 200 & 200 & 256 & 369 & 120 & 296 & 169 & 155 & $3+1$ \\
\hline $\mathbf{N l}$ & 180 & 109 & 9 & 137 & 116 & 137 & 69 & 99 & 129 \\
\hline 60 & 150 & 109 & 190 & 120 & 136 & 147 & 130 & דננ & 113 \\
\hline $5 c$ & 20,5 & & & & & & & & \\
\hline$v$ & 135 & 27] & 123 & 346 & 237 & 216 & 103 & 106 & 35] \\
\hline Ea & 2040 & 156. & 1509 & 363 & 350 & 321 & 376 & 655 & 539 \\
\hline $\mathbf{S r}$ & 222 & 96 & 286 & 200 & 98 & 120 & 97 & 101 & 250 \\
\hline Hf & 4,2 & & & & & & & & \\
\hline $\boldsymbol{7 r}$ & 48 & 30 & 69 & 144 & $|3|$ & 120 & 117 & 128 & 138 \\
\hline $\mathbf{Y}$ & 23 & 22 & 20 & 12 & 19 & 17 & 14 & 23 & 15 \\
\hline Tb & 7,80 & & & & & & & & \\
\hline $\mathbf{u}$ & 1,70 & & & & & & & & \\
\hline
\end{tabular}

\begin{tabular}{|c|c|c|c|c|c|c|c|c|c|c|c|c|c|c|c|c|}
\hline \multirow[b]{2}{*}{ Aroostra } & \multicolumn{16}{|c|}{ Crangs } \\
\hline & 71,40 & 74,25 & 78,75 & 80,65 & 93,90 & 98,90 & 9780 & 126,10 & 133,60 & 191,10 & 211,0 & 21200 & 272 & 273 & 277,50 & 314,14 \\
\hline $\mathrm{SiO}_{2}$ & 74,58 & 62,40 & 63,05 & 56,41 & 66,50 & 6,60 & 96,92 & 69,66 & $67,4]$ & 39,64 & 51.55 & 53,13 & 54.10 & 52,70 & 55.70 & 5831 \\
\hline $\mathrm{THO}_{\mathrm{x}}$ & 0,37 & 0.76 & 0.72 & 0.77 & 0,65 & 0.76 & 0.72 & 0.59 & 0,58 & 0,05 & 1,44 & 1.39 & 1.72 & $\mathrm{l}, \mathrm{t} 2$ & 0,8 & 097 \\
\hline $\mathrm{AH}_{2} \mathrm{O}_{1}$ & 9.73 & 18.57 & 1B,24 & 21.85 & 16,00 & 20,85 & 2087 & 10,01 & 11,25 & 15,85 & 19,48 & 1597 & 18.6 & 14,56 & 25,74 & 16,26 \\
\hline $\mathrm{Frn}_{\mathrm{O}} \mathrm{H}^{*}$ & 5.17 & $\pi, 54$ & 835 & $9 \%$ & 0,76 & 8,9 & 8,15 & 8.59 & 7,60 & 12.58 & 14,01 & 4,51 & 8,60 & 17,29 & 11,09 & 9,04 \\
\hline MnO & 0.52 & nos & 020 & 0,16 & 0,00 & 0.13 & 0.13 & 1,58 & 1,43 & 0,06 & 060 & 0,71 & 0,04 & 0,14 & 0,05 & 0,06 \\
\hline $\mathrm{M}_{5} \mathrm{O}$ & 1,58 & 2,44 & 2.12 & 2.23 & 2.12 & 2,79 & 2,84 & 2.89 & 3.02 & 3.74 & 4,41 & 4,14 & 5,17 & 6,12 & 1,66 & 3,65 \\
\hline $\mathrm{C}+\mathrm{O}$ & 2,53 & 0,75 & 1,15 & 1,13 & 0,68 & 1.76 & 1,83 & 1,4 & 2.29 & 1,35 & 4,83 & 3,50 & 2,28 & 0,94 & 2,40 & 3,53 \\
\hline $\mathrm{N}_{44} \mathrm{O}$ & 1,12 & 1,10 & 1,49 & 1,16 & 1,07 & 1,19 & 1,89 & 0,58 & 1,26 & 1,17 & 3,40 & 3,58 & 4,16 & 1,32 & 0,00 & 2,24 \\
\hline$k \neq 0$ & 1,13 & 3,48 & 2,58 & 3.79 & 287 & 2,93 & 2,5 & 2,22 & 1,59 & 1,22 & 1,94 & 2,42 & 3,32 & 1,72 & 0,00 & 2,69 \\
\hline $\mathrm{P}_{1} \mathrm{O}$ & 0,15 & 0,13 & 0,12 & 0,35 & 0,11 & 0,25 & 0,18 & 0,10 & 0,11 & 0,07 & $0,2,3$ & 0,27 & 0,07 & $0,0 \mathrm{~A}$ & 0,26 & 0,77 \\
\hline PF & 3,54 & 3,42 & 2,79 & 3,66 & 2,75 & 3,70 & 4,15 & 2,12 & 2,95 & 3,43 & 3,01 & 2,00 & 2,25 & 3,96 & 3,40 & 2,95 \\
\hline Total & 99,90 & 99,97 & 10000 & 10080 & $.99,57$ & 99,63 & 99,45 & 99.78 & 104,09 & 99,90 & 300,09 & {$[0], 22$} & 100,31 & 99,87 & 99,99 & 110,47 \\
\hline IAO & 75,74 & 8121 & 2,3 & 81,90 & 81,34 & 8.57 & 82,37 & 75,80 & 76,29 & 81,82 & 70,37 & 71,07 & 78,08 & 83,35 & 95,12 & 72,54 \\
\hline DWAT & 88,4 & 77.06 & 77.56 & 72,08 & 80,60 & 73,14 & 79,23 & 87,43 & 85,69 & 79,00 & 7690 & 77,33 & 74,41 & 78.35 & 6839 & 78,19 \\
\hline $\mathrm{Cr}$ & 120 & 164 & 190 & J81 & 145 & 188 & 176 & 87 & 110 & 166 & 240 & 200 & 200 & 134 & 239 & 213 \\
\hline Mi & 80 & 6 & 67 & $\mathbf{8 I}$ & 75 & 86 & 89 & 112 & 100 & $\boldsymbol{r}$ & 120 & 110 & 87 & $\$ 10$ & 66 & 59 \\
\hline Co & 210 & 124 & 136 & 157 & 210 & 192 & 153 & 200 & 200 & 218 & 210 & 220 & 117 & 224 & 135 & 196 \\
\hline St & & & & & & & & 15 & 14 & & & & 42 & 30 & -27 & 23 \\
\hline$v$ & 59 & 98 & 91 & [1] & 96 & 123 & 114 & 132 & 128 & 121 & 364 & 315 & t14 & $16 \mathrm{~L}$ & 199 & 165 \\
\hline $\mathrm{B3}$ & $60 s$ & 794 & 740 & 799 & 1000 & 990 & 636 & 652 & 514 & 704 & 1269 & 1200 & 501 & 255 & 1469 & 1141 \\
\hline Sr & 447 & 198 & 204 & 170 & 200 & 243 & 237 & 47 & 220 & BB & $4 ! 2$ & 309 & 100 & 26 & $3 \neq 2$ & S40 \\
\hline Hit & & & & & & & & 2,40 & 2,40 & 3,800 & & & 4,20 & 4,40 & 3,70 & 2,72 \\
\hline $\mathbf{z}$ & 44 & 65 & 116 & 74 & 44 & at & 61 & 30 & 59 & 61 & 73 & 47 & 182 & 197 & $\$ 9$ & 10 \\
\hline $\mathbf{r}$ & 18 & 16 & 20 & 29 & 16 & 22 & 20 & IS & 16 & 23 & 26 & 31 & 12 & 64 & 14 & 13 \\
\hline$T \mathbf{h}$ & & & & & & & & 6.75 & 7,37 & 12,10 & & & 2,83 & 9,90 & 2,87 & 2,13 \\
\hline $\mathbf{u}$ & & & & & & & & 1,40 & $1,0 \mathrm{H}$ & 2.10 & & & 14,00 & 16,00 & 0.84 & 1,00 \\
\hline
\end{tabular}

Cerca de $48 \%$ das amostras possuem um IAQ entre 70 e 80 , intervalo este que inclui a variação observada nos folhelhos pós-arqueanos, parte do intervalo observado em illita, montmorilonita e beidelita e o da moscovita. Por outro lado, cerca de $35 \%$ das amostras possuem um IAQ situado no limite superior do calculado para illita, montmorilonita e beidelita, parte do intervalo de argilas residuais e o de argilas do delta do rio Amazonas. Apenas $2 \%$ das amostras possuem um IAQ de condições de intemperismo extremo.

Do exposto se conclui que as proporções de $\mathrm{Al}_{2} \mathrm{O}_{3}, \mathrm{Na}_{2} \mathrm{O}$, $\mathrm{K}_{2} \mathrm{O}$ e $\mathrm{CaO}$ da maioria das amostras analisadas podem, empiricamente, ser explicadas por intemperismo químico mo- derado na área-fonte e similares às inferidas para justificar sedimentos e rochas sedimentares argilosos pós-arqueanos, de área-fonte conhecida, e seus equivalentes metamórficos. Isto assegura uma comparação das propriedades geoquímicas das amostras analisadas com os padrões internacionais de rochas sedimentares pós-arqueanas.

Comportamento Geral de Elementos Maiores, Menores e Traços A Tabela VII contém a média dos óxidos e elementos traços das amostras analisadas, excluídos os dados do horizonte anômalo de Guarinos. Os xistos carbonosos de Crixás são mais ricos em $\mathrm{SiO}_{2}, \mathrm{CaO}, \mathrm{Na}_{2} \mathrm{O}, \mathrm{P}_{2} \mathrm{O}_{5}$, 
Tabela IV - Composição química de xistos carbonosos (FC), metafolhelhos (IAM) e metarenitos (MGR) do horizonte anômalo intercalado em metaturbiditos do greenstone belt de Guarinos. Óxidos em \% de peso, IAQ e IMATem \% e elementos traço em ppm.

Table IV - Chemical composition of carbonaceous schist (FC), metashales (LAM), and metarenites (MGR) of the anomalous horizon intercalated in metaturbidites of the Guarinos greenstone belt. Oxides in weight \%, IAQ and IMAT in \%, and trace elements in ppm.

\begin{tabular}{|c|c|c|c|c|c|c|c|c|}
\hline Amostr & SED-15 & SED-20 & SED-25 & 198.00 & 200 & 20600 & 234 & 235.00 \\
\hline Roche & $\mathbf{F C}$ & $\mathbf{F C}$ & $\mathrm{FC}$ & LAM & LAM & LAM & MGR & MOR \\
\hline $\mathrm{SiO}_{2}$ & 42,36 & 46,47 & 46.21 & 46,94 & 47,51 & 44,21 & 53,60 & 36,43 \\
\hline $\mathrm{THO}_{2}$ & n,94 & 0,62 & 1,16 & 1.18 & 1.10 & 1.13 & 0,64 & 1,54 \\
\hline $\mathrm{Al}_{7} \mathrm{O}_{3}$ & 872 & 8,96 & 11,17 & 9,77 & 7.60 & $10 ; 35$ & 5,31 & 12,7 \\
\hline $\mathrm{Fe}_{4} \mathrm{O}_{3}$ & 13,80 & 12,99 & 12,00 & 13,02 & 13,46 & 12,86 & 12,61 & 15,31 \\
\hline MnO & 0,13 & 0,15 & A, 16 & 0,44 & 0,15 & $0 ; 13$ & 0,13 & 0,13 \\
\hline $\mathrm{MgO}$ & 22,00 & $\mathbf{J 8 ; 4 !}$ & 13,04 & $i 6,44$ & 16,94 & 18,57 & 12,47 & 21,26 \\
\hline Cno & 5,46 & B,75 & 4,93 & 8,32 & 10,38 & 7,62 & 9,50 & 5,39 \\
\hline$N_{120}$ & 0,34 & 1,16 & 0,30 & 1,14 & 1,05 & 0,82 & 0,95 & 0,62 \\
\hline $\mathrm{K}_{1} \mathrm{O}$ & 0,20 & 0,20 & 3.05 & $1,0 \mathrm{Am}$ & 0.26 & 0.29 & 0,23 & 0,20 \\
\hline $\mathrm{POO}$ & 0,09 & 0,05 & 0,03 & 0,08 & 0,02 & 0,13 & 0,12 & 0,13 \\
\hline PF & $\mathbf{6 , 0 1}$ & 3,35 & 8,67 & 3,001 & 2,95 & 3, 185 & 4,47 & 6,01 \\
\hline Toun: & 98,93 & 99,98 & 99,97 & 99,95 & 99,85 & 99,96 & 99,48 & 100,32 \\
\hline IAQ & 5923 & 46,96 & 57,42 & 6099 & $\$ 3,56$ & 67,61 & 46,82 & 78,26 \\
\hline IMAT & 829 & 835 & \$.53 & 82.7 & 86.10 & 81.03 & $90.9 \mathrm{a}$ & 74.15 \\
\hline $\mathrm{Cr}$ & 1976 & 1354 & 1699 & 1429 & 1590 & 1708 & 1268 & 1646 \\
\hline $\mathbf{N i}$ & 863 & 448 & 1413 & 663 & 700 & 663 & 380 & 290 \\
\hline Co & 101 & 100 & 190 & 210 & 199 & 201 & (3) & $\$ 23$ \\
\hline Se & & & & 34 & 31 & 29 & 21 & 36 \\
\hline$v$ & 218 & J81 & 185 & 219 & 201 & 218 & 178 & 266 \\
\hline Ba & LSO & 100 & 86 & 184 & 125 & 100 & 100 & $\mathbf{8 0}$ \\
\hline $\mathbf{S r}$ & 123 & 300 & 190 & 250 & 300 & 210 & 300 & 121 \\
\hline Hf & & & & 8.70 & 1,80 & 1,60 & 0,22 & 1,60 \\
\hline $\mathbf{z} r$ & 54 & 12 & 108 & [II] & 56 & 55 & 87 & 117 \\
\hline $\mathrm{Y}$ & 25 & 40 & 26 & 17 & 11 & 14 & 26 & 13 \\
\hline Th & & & & & & & 0,22 & 0,42 \\
\hline u & & & & & & & 0,00 & 0,00 \\
\hline
\end{tabular}

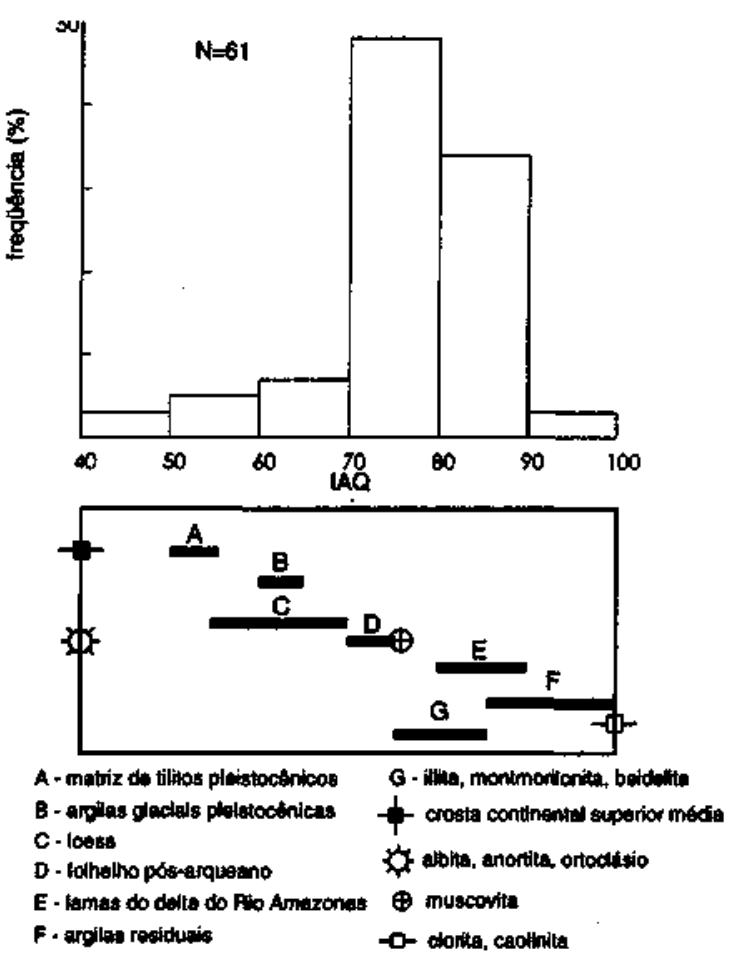

Figura 3 - Freqüencia do índice de Alteração Química (IAQ) de área-fonte que justificaria a composição química das rochas metassedimentares detríticas dos greenstone belts de Crixás e Guarinos. IAQ $=\left[\mathrm{Al}_{2} \mathrm{O}_{3} /\left(\mathrm{Al}_{2} \mathrm{O}_{3}+\mathrm{Na}_{2} \mathrm{O}+\mathrm{K}_{2} \mathrm{O}+\right.\right.$ $\mathrm{CaO})] \times 100$.

Figure 3 - Frequency of the Chemical Alteration Index (IAQ) of the source area that could justify que chemical composition of the detrital metasedimentary rocks of the Crixás and Guarinos greenstone belts. IAQ = $\left[\mathrm{Al}_{2} \mathrm{O}_{3} /\left(\mathrm{Al}_{2} \mathrm{O}_{3}+\mathrm{Na}_{2} \mathrm{O}+\mathrm{K}_{2} \mathrm{O}+\mathrm{CaO}\right)\right] \times 100$.

Tabela V - Proporções de Elementos Terras Raras (ETR) em ppm, de xistos carbonosos, metafolhelhos e metarenitos dos greenstones belts de Crixas e Guarinos.

Table V - REE proportions (ppm) of carbonaceous schists, metashales and metarenites of the Crixás and Guarinos greenstone belts.

\begin{tabular}{|c|c|c|c|c|c|c|c|c|c|c|c|c|c|c|c|c|c|c|}
\hline \multirow[b]{3}{*}{ Amosun } & \multicolumn{7}{|c|}{ Xistos Cutponosos } & \multirow{2}{*}{\multicolumn{3}{|c|}{$\begin{array}{c}\text { Metafollhellhos } \\
\text { Oruinos } \\
\end{array}$}} & \multicolumn{8}{|c|}{ Meterenikx } \\
\hline & \multirow{2}{*}{$\frac{\text { Crixts }}{2}$} & \multicolumn{6}{|c|}{ Guminos } & & & & \multirow{2}{*}{$\frac{\text { Crinit }}{3}$} & \multicolumn{7}{|c|}{ Guarinos } \\
\hline & & 4450 & 45,50 & 6059 & $14 L, 70$ & SED- 30 & $92-131-161$ & .298 & 300 & $92-\pi-190$ & & 126,10 & 133,60 & 191,00 & $2 T 2$ & 273 & 277,50 & 314,00 \\
\hline La & 24,80 & 31,30 & 42,40 & 19.00 & 27,50 & 15,93 & $5.8 B$ & 20,00 & 25,90 & 3653 & 36,26 & 21,40 & 23,50 & 34,00 & 18,70 & 57,00 & 19,70 & 14,13 \\
\hline$C_{c}$ & 44,90 & 55,20 & 68,00 & 34,70 & 65,00 & 51,42 & 32,73 & 41,60 & 53,40 & 37.67 & 72,60 & 49,00 & 51,00 & 67,90 & 36,50 & 102,10 & 38,90 & 29,60 \\
\hline Nd & 22,94 & 30.00 & 41,00 & 20,00 & 33,00 & 26,36 & 9,32 & 29.60 & 30,30 & 39,24 & 31,40 & 16,40 & 22,00 & 26,00 & 26,00 & 54,00 & 19,00 & 19,80 \\
\hline $\mathbf{S m}$ & $3, \pi 7$ & 6,20 & 8,10 & 3,93 & 9,00 & 5,82 & $2,4 !$ & 4,60 & 5,50 & 6,53 & 5,90 & 3,32 & 350 & 6,10 & 6,92 & 11,47 & 4,34 & 3,40 \\
\hline Eu & 1,13 & 1,63 & 3.00 & 1,20 & 1.7 & 1,27 & 0,55 & 1,30 & 1,80 & 1,22 & 1,63 & 0,91 & 0,96 & 1,53 & 2,45 & 5,44 & 1,23 & 1,08 \\
\hline Gd & & & & & & 491 & 2,17 & & & 4,84 & & & & & & & & \\
\hline $\mathbf{T b}$ & 0,29 & 0,90 & 1,90 & 0.40 & 1,93 & & & 0,69 & 0,72 & & 0,72 & 0,47 & & 0,82 & 1,25 & 1,90 & 0,69 & 0,40 \\
\hline Dy & & & & & & 5,7 & 2,27 & & & 4,83 & & & & & & & & \\
\hline Ho & & & & & & $t, 15$ & 0,47 & & & 0,96 & & & & & & & & \\
\hline Er & & & & & & 3,17 & 1,36 & & & 2,60 & & & & & & & & \\
\hline $\mathbf{Y b}$ & 1,35 & 1.60 & 6,80 & 4,40 & 7,00 & 2,78 & 1,42 & 2,20 & 2,20 & 2,15 & 2,61 & 1,30 & L,40 & 2,36 & 4,30 & 6,200 & 1,93 & 1,30 \\
\hline Le. & 0.21 & 0,16 & 0,96 & 0,77 & 1,06 & 0,33 & 0,19 & 0,35 & 0,42 & 027 & 04 & 0.26 & 0,22 & 0,38 & 070 & 1,00 & 0,27 & 0,24 \\
\hline
\end{tabular}

$\mathrm{Cr}$, Ba e Sr que os de Guarinos, por sua vez mais ricos em $\mathrm{Fe}_{2} \mathrm{O}_{3}{ }^{*}, \mathrm{MnO}, \mathrm{MgO}, \mathrm{Ni}, \mathrm{Co}, \mathrm{Cu}$ e $\mathrm{Y}$, mas se eqüivalem em $\mathrm{TiO}_{2}, \mathrm{Al}_{2} \mathrm{O}_{3}, \mathrm{~K}_{2} \mathrm{O}$, V e Zr. As menores proporções de $\mathrm{SiO}_{2} \mathrm{e}$ maiores de $\mathrm{Fe}_{2} \mathrm{O}_{3}$ * e Perda ao Fogo dos xistos de Guarinos são devidas a uma abundância maior de matéria carbonosa.

Os metafolhelhos de Crixas são mais ricos em $\mathrm{TiO}_{2}, \mathrm{MgO}$, $\mathrm{K}_{2} \mathrm{O}, \mathrm{P}_{2} \mathrm{O}_{5}, \mathrm{Cr}$ e $\mathrm{Zr}$, que os de Guarinos, mais ricos em $\mathrm{SiO}_{2}$, $\mathrm{CaO}, \mathrm{Na}_{2} \mathrm{O}, \mathrm{Ni}, \mathrm{Co}, \mathrm{Ba}$ e $\mathrm{Sr}$, com proporções comparáveis de $\mathrm{Al}_{2} \mathrm{O}_{3}, \mathrm{Fe}_{2} \mathrm{O}_{3}$ * $, \mathrm{MnO}, \mathrm{V}, \mathrm{Cu}$ e $\mathrm{Y}$. Por outro lado, os metarenitos de Crixas são mais ricos em $\mathrm{TiO}_{2}, \mathrm{Fe}_{2} \mathrm{O}_{3}{ }^{*}, \mathrm{Cr}, \mathrm{Ni}, \mathrm{V}$ e $\mathrm{Zr}$ que os de Guarinos, mais ricos em $\mathrm{SiO}_{2}, \mathrm{MnO}, \mathrm{Co}, \mathrm{Cu}, \mathrm{Ba}, \mathrm{Sr}$ e Y. As proporções de $\mathrm{Al}_{2} \mathrm{O}_{3}, \mathrm{MgO}, \mathrm{CaO}, \mathrm{Na}_{2} \mathrm{O}, \mathrm{K}_{2} \mathrm{O}$, e $\mathrm{P}_{2} \mathrm{O}_{5}$ de metarenitos de ambas faixas são comparáveis.

Daí se conclui que não há um padrão geoquímico notável dos três litótipos entre as duas faixas, exceto o $\mathrm{Cr}$ mais abundante em Crixás independente do litótipo. Aparentemente não existem razões petrográficas óbvias para as diferenças, exceto pela variação de óxidos de alguns elementos maiores, em particular $\mathrm{SiO}_{2}, \mathrm{Al}_{2} \mathrm{O}_{3}, \mathrm{Fe}_{2} \mathrm{O}_{3}{ }^{*}, \mathrm{Na}_{2} \mathrm{O}$ e $\mathrm{K}_{2} \mathrm{O}$ que poderiam ser justificadas pelas variações nas proporções de quartzo, clorita e/ou biotita, sericita e minerais opacos entre litótipos equivalentes. 
Tabela VI - Proporções de Elementos Terras Raras (ETR) em ppm, de xistos carbonosos (FC), metafolhelhos (LAM) e metarenitos (MGR) do horizonte anômalo intercalado em metaturbiditos do greenstone belt de Guarinos. Table VI - Rare Earth Elements (REE) proportions (ppm) of carbonaceous schists (FC), metashales (LAM), and metarenites (MGR) of the anomalous horizon intercalated in metaturbidites of the Guarinos greenstone belt.

\begin{tabular}{|c|c|c|c|c|c|c|c|}
\hline Ambolth & SED-20 & SED-25 & 19:00 & 200 & 206.00 & 234 & 235.00 \\
\hline Rochs & $\mathrm{PC}$ & $\mathbf{F C}$ & LAM & LAM & LAM & MOR & MGR \\
\hline L & $11, \infty 0$ & 12,54 & 5,33 & 3,70 & 5,70 & 7,10 & 4,80 \\
\hline Ce & 8,07 & $16,4 \mathrm{t}$ & 14,44 & 11,25 & 15,00 & $17, \infty 0$ & 13,20 \\
\hline Nd & 16,99 & 14,98 & 7,5 & 7,30 & 11,00 & 13,90 & 7,70 \\
\hline Sm & $4, \theta 9$ & 3.68 & 2,88 & 2.28 & 2,46 & 4,24 & 2,34 \\
\hline E. & 1.43 & 0,93 & 1,21 & 1,12 & 1,05 & 0,74 & 0,7 \\
\hline Gd & 5,27 & 3,73 & & & & & \\
\hline $\mathbf{T b}$ & & & 0.50 & 0,33 & 0,62 & 0,80 & 0.70 \\
\hline Dy & 5,37 & 3,94 & & & & & \\
\hline $\mathrm{Ha}$ & 1,00 & 0,82 & & & & & \\
\hline $\mathbf{E}$ & 2,38 & 2,36 & & & & & \\
\hline Yb & 1,55 & 1,92 & 2,00 & 1,32 & 1,60 & 2,20 & 1,40 \\
\hline Lu & 0,16 & 0,25 & 0,25 & 0,17 & 0,21 & 0,27 & $0, \mathrm{tg}$ \\
\hline
\end{tabular}

Por outro lado, comparando as médias das composições do total de amostras dos três litótipos entre si (Tabela VIIIA), alguns padrões se destacam, os quais devem ser interpretados à luz de três aspectos. Primeiro, que os xistos carbonosos e metafolhelhos formaram-se, respectivamente em ambiente anóxico e óxico, o que permite comparar estes litótipos sob o ponto de vista da infuência da participação de compostos orgânicos sobre a distribuição dos óxidos e elementos traços. Segundo, que xistos carbonosos e metaturbiditos não são rochas estratigraficamente equivalentes, o que permite comparar a composição dos litótipos estratigráficos precoces com os tardios. Terceiro, que metafolhelhos e metarenitos estão geneticamente relacionados, o que permite comparar a sua composição quanto aos efeitos do fracionamento granulométrico e mineralógico durante a sedimentação.

Tabela VII - Composição química média de xistos carbonosos, metafolhelhos e metarenitos das faixas Crixás e Guarinos.

Table VII - Average chemical composition of carbonaceous schist, metashales, and metarenites, of the Crixás and Guarinos greenstone belts.

\begin{tabular}{|c|c|c|c|c|c|c|}
\hline & \multicolumn{2}{|c|}{ Xisas Cumonotos } & \multicolumn{2}{|c|}{ Melufothethos } & \multicolumn{2}{|c|}{ Metarenitos } \\
\hline & $\begin{array}{l}\text { Crixds } \\
(\mathrm{N}=8)\end{array}$ & $\begin{array}{c}\text { Gumprims } \\
(\mathrm{N}=6)\end{array}$ & $\begin{array}{l}\text { Crixfik } \\
(N=1)\end{array}$ & $\begin{array}{c}\text { Cuorimos } \\
(\mathrm{N}=7)\end{array}$ & $\begin{array}{l}\text { Crixts } \\
(1-9)\end{array}$ & $\begin{array}{l}\text { Gu-inos } \\
(\mathrm{N}=16)\end{array}$ \\
\hline $\mathrm{SiO}_{2}$ & 60,45 & 96,06 & 54,91 & 51,25 & $57 \mu$ & 59,92 \\
\hline $\mathrm{THO}_{2}$ & 0,97 & 0,87 & $1,0 A$ & 0,82 & $1, M$ & 0,8 \\
\hline $\mathrm{Al}_{2} \mathrm{O}_{3}$ & 14.37 & 14,19 & 39,42 & 18,70 & 16,17 & 16.83 \\
\hline $\mathrm{Fe}_{2} \mathrm{O}_{3} \cdot$ & 8,64 & 10,64 & 8,93 & 9,14 & 12,10 & 9,84 \\
\hline $\operatorname{MnO}$ & 0,12 & $0.2 k$ & 0,05 & 0,09 & 0,07 & 0,37 \\
\hline $\mathrm{M}_{8} \mathrm{O}$ & 3,48 & 4,18 & 4,69 & 3,61 & 9,78 & 3,22 \\
\hline cro & 2,44 & 0,45 & 0,72 & 1,37 & 1,92 & 2,05 \\
\hline $\mathrm{N} 2 \mathrm{O} \mathrm{O}$ & 2,14 & 0,38 & 0.73 & 1,48 & 1,68 & 1,70 \\
\hline$K_{-5}=$ & 2,26 & 2.75 & 4,32 & 3,49 & 2,45 & 2,33 \\
\hline $\mathrm{P}_{2} \mathrm{O}_{3}$ & 0,13 & 0,06 & 0,29 & 0,19 & B,14 & 0,17 \\
\hline P,F & 4,97 & 10,22 & 4,45 & 4,18 & 3,17 & 3,10 \\
\hline Le & 34,75 & 81,66 & 80,03 & 79,29 & 78,43 & 79,49 \\
\hline IMAT & 81,12 & 79,78 & 73,87 & 76,33 & 79,31 & $n, 9$ \\
\hline $\mathrm{Cr}$ & 180 & 165 & 250 & 198 & 234 & 172 \\
\hline Ní & 174 & 251 & 83 & 167 & 118 & $B 5$ \\
\hline Co & 158 & 191 & 83 & 167 & 125 & IBA \\
\hline$v$ & 161 & 165 & 139 & 131 & 209 & 149 \\
\hline Cu & $\infty$ & 143 & 44 & 38 & 32 & B3 \\
\hline Bn & 1575 & 1062 & 936 & 1020 & 698 & 811 \\
\hline st & 104 & 39 & 49 & 185 & 158 & 236 \\
\hline $\mathrm{zr}$ & 87 & 84 & 141 & 89 & 102 & 75 \\
\hline$Y$ & 17 & 42 & 23 & 20 & 18 & 22 \\
\hline
\end{tabular}

(1) = Filitos Carbonosos; (2) = Metafolhelhos; (3) = Metarenitos
Uma análise dos valores médios constantes da Tabela VIIIA sugerem que a presença de matéria orgânica nos xistos carbonosos, comparativamente aos metafolhelhos, aparentemente se manifesta, ao mesmo tempo, como diluidor e concentrador. $\mathrm{Na}$ ausência de apatita, Cr-espinélios e zircão, as proporções menores de $\mathrm{Al}_{2} \mathrm{O}_{3}, \mathrm{P}_{2} \mathrm{O}_{5}, \mathrm{Cr}, \mathrm{Sr}$ e $\mathrm{Zr}$ dos xistos carbonosos podem ser atribuídas à diluição por matéria carbonosa que, no ambiente anóxico, compete com argilo-minerais. $\mathrm{O}$ efeito concentrador da matéria orgânica é sugerido pelas proporções maiores de $\mathrm{MnO}, \mathrm{Ni}, \mathrm{Co}, \mathrm{V}$ e $\mathrm{Cu}$ nos xistos carbonosos. Contudo, é incerto se estas concentrações residem preferencialmente na matéria carbonosa ou provêm dos minerais micáceos coexistentes. Anomalias de Ni, Co e V em óleo crú são atribuídas por Kapo (1978) e Barwise \& Whitehead (1983) não à atividade orgânica em si, mas à propriedade de quelantes do tipo metal-porfina de trocar elementos em ligação fraca, como $\mathrm{Mg}$, por elementos com ligações termodinamicamente mais estáveis, como $\mathrm{Ni}$ e $\mathrm{V}$, existentes em argilo-minerais durante o decaimento e diagênese da matéria orgânica.

Tabela VIII - (A) - Composição química média de rochas metassedimentares detríticas dos greenstone belts de Crixás e Guarinos, calculada a partir dos doidos das Tabelas l, $\mathrm{He}$ III. (B) - Composição química médias das rochas metassedimentares detríticas do horizonte anômalo do greenstone belt de Guarinos, calculada a partir da Tabela IV.

Table VIII - (A) - Average chemical composition of the detrital metasedimentary rocks of the Crixás and Guarinos greenstone belts, as calculated from Tables I, II and III. (B) - Average chemical composition of detrital metassedimentary rocks of the Guarinos greenstone belt anomalous horizon, calculated from Table IV.

\begin{tabular}{|c|c|c|c|}
\hline & \multicolumn{3}{|c|}{$\bar{A}$} \\
\hline & (I) & (b) & (3) \\
\hline $\mathrm{SiO}_{2}$ & 59.23 & 96.98 & 38,68 \\
\hline $\mathrm{TiO}_{k}$ & 0.87 & 0.93 & 0.95 \\
\hline AKO, & 14.28 & 19.06 & 16.50 \\
\hline $\mathrm{FeO}_{2} \mathrm{O}^{*}$ & 9.64 & 9.03 & 10,97 \\
\hline MnO & 0.25 & 0.07 & 0.22 \\
\hline $\mathrm{MgO}$ & 3.83 & 3.85 & 3.50 \\
\hline $\mathrm{CuO}$ & 1.44 & 1.04 & 1.98 \\
\hline $\mathrm{N}=\mathrm{O}$ & 1.26 & 1.12 & [.69 \\
\hline K.9O & 2.50 & 3.90 & 2.39 \\
\hline $\mathrm{P} \neq \mathrm{O}$ & 0,09 & 0.23 & 0.15 \\
\hline P.F. & 7.59 & 4.3] & 3.13 \\
\hline IAO & 78.20 & 79.66 & 78.66 \\
\hline MAT & 79,95 & 1310 & 78.64 \\
\hline $\mathrm{Cr}$ & $\mathrm{J} 77$ & 224 & 209 \\
\hline $\mathbf{N i}$ & 212 & 125 & tot \\
\hline Co & 174 & 125 & 205 \\
\hline $\mathbf{v}$ & 163 & 135 & 179 \\
\hline$C_{\mu}$ & 106 & $4 I$ & 57 \\
\hline B4 & I3I8 & 97 & 769 \\
\hline $\mathbf{s r}$ & 71 & 117 & 197 \\
\hline $\mathbf{z}$ & 85 & 115 & $\Delta$ \\
\hline$Y$ & 29 & $2 t$ & 20 \\
\hline
\end{tabular}

\begin{tabular}{|c|c|c|}
\hline \multicolumn{3}{|c|}{ B } \\
\hline (b) & (3) & (3) \\
\hline 49.01 & 46.09 & 45.01 \\
\hline 0.89 & $t .14$ & 1.09 \\
\hline 9.62 & 9.24 & 9.90 \\
\hline 12.93 & {$[3.1]$} & 13.96 \\
\hline 0.15 & 0.14 & 0.13 \\
\hline 17.84 & 17.32 & 18.67 \\
\hline 6.38 & $g, 77$ & 7,44 \\
\hline 0.60 & 1.00 & 0.78 \\
\hline 1,15 & 0.54 & 0.22 \\
\hline 0.06 & 000 & 0.12 \\
\hline 6.01 & 3.26 & 5.21 \\
\hline 54.54 & 54.72 & 62.59 \\
\hline 82.42 & 83,30 & 32.56 \\
\hline 1676 & 1578 & 1454 \\
\hline 900: & 742 & 335 \\
\hline 113 & 203 & 127 \\
\hline 194 & 213 & 222 \\
\hline 25 & 51 & 7 \\
\hline 112 & 136 & 90 \\
\hline 174 & 253 & 210 \\
\hline $5 B$ & 74 & 102 \\
\hline 30 & 14 & 19 \\
\hline
\end{tabular}

Contudo, isto não implica em eliminar a propriedade natural de microrganismos, como as bactérias metanogênicas para nos adaptar a uma circunstância arqueana, de concentrar elementos traços (Lancaster 1979, Thauer 1981). Assim, é provável que concentrações maiores de $\mathrm{Ni}$, Co e V nos xistos carbonosos se justificam pelo efeito combinado da atividade bacteriana e de argilo-minerais ricos nestes elementos.

Abstraídas as proporções de óxidos e elementos traços dos xistos carbonosos que excedem o bakground dos litótipos óxicos por influência da atividade bacteriana, os dados analíti- 
cos permitem concluir que a composição química dos litotipos analisados não obedece a um controle estratigráfico. Isto, por outro lado, indica que tanto os protólitos dos xistos carbonosos quanto dos metafolhelhos e metarenitos devem ter se formado às custas de áreas-fonte composicionalmente idênticas.

Por outro lado, comparando a composição média (Tabela VIIIA) dos metarenitos com a dos metafolhelhos, sob o prisma de um par geneticamente associado de ritmos dos metaturbiditos, as seguintes observações merecem destaque, segundo a ordem deposicional positivamente granoclassificada:

1. A diferença composicional entre metarenitos e metafolhelhos mostra claramente que, em média, os protólitos arenosos não foram ortoquartzíticos, mas areno-argilosos;

2. Como esperado, há uma discreta diminuição de $\mathrm{SiO}_{2} \mathrm{e}$ aumento de $\mathrm{Al}_{2} \mathrm{O}_{3}$ dos metarenitos aos metafolhelhos, decorrente de uma diminuição na quantidade de quartzo detrítico em benefício de argilo-minerais, também refletida na Perda ao Fogo;

3. Concomitante com a variação de $\mathrm{SiO}_{2}$ e $\mathrm{Al}_{2} \mathrm{O}_{3}$, há um discreto aumento de $\mathrm{MgO}$ e $\mathrm{K}_{2} \mathrm{O}$, refletindo a variação de clorita e mica branca, e diminuição de $\mathrm{CaO}, \mathrm{Na}_{2} \mathrm{O}$ e $\mathrm{Sr}$, talvez como reflexo da retenção de traços de plagioclásio na fração areia;

4. $\mathrm{O}$ decréscimo nas proporções de $\mathrm{Fe}_{2} \mathrm{O}_{3}$ e $\mathrm{MnO}$ poderia ser atribuído à presença de magnetita como mineral denso dos metarenitos. Contudo, como o mineral ocorre em traços, é mais provável que este decréscimo resulte da variação na razão mica branca/clorita \pm biotita. $\mathrm{O}$ argumento para tanto reside na ausência de variação do $\mathrm{TiO}_{2}$, mesmo com a presença de ilmenita, em traços, nos metarenitos, indicando que as variações químicas são mais sensíveis às dos minerais micáceos. Já o decréscimo de Co e V pode estar associado com o desaparecimento de magnetita e ilmenita com a granoclassificação;

5. $\mathrm{O}$ aumento de $\mathrm{P}_{2} \mathrm{O}_{5}$, Cr e $\mathrm{Zr}$ dos metarenitos para os metafolhelhos mostra, com clareza, que estes participam da composição de minerais micáceos e que as fases minerais detríticas densas são geoquimicamente insignificantes, um aspecto importante na modelagem da área-fonte.

A Tabela VIIIB contém a média da composição dos xistos carbonosos, metafolhelhos e metarenitos do horizonte anômalo de Guarinos. Os maiores contrastes entre os equivalentes anômalos e não anômalos (Tabela VIIIA) residem nas proporções significativamente menores de $\mathrm{SiO}_{2}, \mathrm{Al}_{2} \mathrm{O}_{3}$, $\mathrm{Na}_{2} \mathrm{O}, \mathrm{K}_{2} \mathrm{O}$, Ba e $\mathrm{Cu}$, e maiores de $\mathrm{Fe}_{2} \mathrm{O}_{3}, \mathrm{MgO}, \mathrm{CaO}, \mathrm{Cr}$, Ni, $\mathrm{V}$ e Sr do horizonte anômalo. Isto indica que a deposição do mesmo ocorreu sob a influência dos níveis de basaltos komatíiticos com os quais se intercalam.

As proporções de matéria carbonosa, em geral inferiores a $2 \%$, não se manifestam como efeito diluidor nas proporções de óxidos de elementos maiores, como observado nas demais situações estratigráficas. $\mathrm{O}$ efeito concentrador se manifesta apenas nas proporções de $\mathrm{Ni}$ dos xistos carbonosos.

Em lâmina delgada, os metarenitos desse horizonte são mais micáceos que os dos metaturbiditos estratigraficamente soto-e sobrepostos, o que, claramente, se manifesta nas proporções de $\mathrm{Al}_{2} \mathrm{O}_{3}$. Apesar de equivalentes em $\mathrm{Al}_{2} \mathrm{O}_{3}$, os metarenitos possuem proporções discretamente menores de $\mathrm{CaO}, \mathrm{Na}_{2} \mathrm{O}$ e $\mathrm{K}_{2} \mathrm{O}$ que os metafolhelhos, em resposta ao aumento na quantidade de minerais micáceos. É importante observar que, exceto $\mathrm{Zr}$ e $\mathrm{Y}$, os teores dos demais elementos traços aumentam no mesmo sentido, indicando a importância da fração argila dos protólitos como meio de retenção destes elementos.

As características geoquímicas do horizonte anômalo são bizarras, pois, exceto pelas proporções mais baixas de $\mathrm{CaO}$, as dos demais óxidos se assemalham às de um piroxenito, as de $\mathrm{Cr}$ e $\mathrm{Ni}$ às de dunito e os demais às de basaltos. Isto abre caminho para uma reinterpretação estratigráfica da seqüência sedimentar de Guarinos e um prognóstico de sua ocorrência, ainda desconhecida, repetição em Crixás. A intensa deformação do greenstone belt de Guarinos induz interpretar os xistos carbonosos situados em meio a metaturbiditos como repetições tectônicas dos níveis estratigráficos inferiores. A sua geoquímica mostra, no entanto, que o regime turbidítico foi submetido a períodos de quiescência que deram lugar a recurrências do regime anóxico e que nem todas as repetições são tectônicas.

DIAGRAMAS DE VARIAÇÃO Para melhor destacar as semelhanças e diferenças entre xistos carbonosos, metafolhelhos e metarenitos de Crixás e Guarinos, e identificar tendências composicionais, empregaram-se alguns diagramas bivariantes. Os diagramas permitem testar, monitorar e conhecer o comportamento dos óxidos de elementos maiores e elementos traços frente a um índice empírico de maturidade sedimentar, identificar as relações recíprocas entre $\mathrm{CaO}$, $\mathrm{Na}_{2} \mathrm{O}$ e $\mathrm{K}_{2} \mathrm{O}$ e descrever as características das assinaturas dos Elementos Terras Raras (ETR) nas rochas estudadas.

Variação dos Óxidos de Elementos Maiores com o índice de Maturidade Com o objetivo de comparar as rochas estudadas entre si e identificar eventuais padrões de variações de composição, os dados de óxidos de elementos maiores foram plotados versus um índice empírico de maturidade mineral dado pela razão:

$$
\mathrm{IMAT}=\mathrm{SiO}_{2} /\left[\mathrm{SiO}_{2}+\mathrm{Al}_{2} \mathrm{O}_{3}\right] \times 100
$$

Teoricamente, o $\mathrm{Al}_{2} \mathrm{O}_{3}$ e parte de $\mathrm{SiO}_{2}$ expressam a participação de argilo-minerais da matriz de rochas sedimentares detríticas, ou seus equivalentes metamórficos, e o restante de $\mathrm{SiO}_{2}$, o quartzo detrítico. Pela expressão, na medida em que $\mathrm{Al}_{2} \mathrm{O}_{3}$ tende a zero, a participação de argilo-minerais nos protólitos também tende a zero, aproximando-se de IMAT $=100$, que deve corresponder a um arenito ortoquartzítico, como mostra a variação de IMAT da Tabela IX. As variações dos diversos óxidos de elementos maiores das amostras de referência da Tabela IX com o IMAT são quase-lineares, decrescentes ou crescentes, conforme o caso, sugerindo uma consistência petrológica sedimentar.

A figura 4 mostra a variação dos óxidos maiores das amostras estudadas com o IMATT. Os diagramas não distinguem xistos carbonosos, metafolhelhos e metarenitos pela variação dos óxidos de elementos maiores e menores e de elementos traços. Daí se conclui que os três litotipos são composicionalmente equivalentes, como já observado, quando se comparou as médias das composições.

Nos diagramas, a amostra com o menor valor do IMAT é um metasiltito com proporções semelhantes de quartzo e clorita+mica branca, as últimas na proporção de $2: 1$, com biotita e granada subordinadas. A amostra com IMAT maior é um xisto carbonoso com cerca de $5 \%$ de clorita e de $3 \%$ de matéria carbonosa. A abundância de quartzo recristalizado com inclusões de matéria carbonosa, combinada com as baixas proporções de clorita poderiam sugerir um metacfem. Entretanto, a presença de zircão, epidoto, ilmenita e albita, ainda que raros e, na maioria, intersticiais ao quartzo indicam tratar-se de um metarenito, com um IMAT próximo ao de um subarcósio.

As figuras $4 \mathrm{a}$ e $4 \mathrm{~b}$ testam o IMAT com as amostras estudadas. Como esperado, $\mathrm{SiO}_{2}$ cresce e $\mathrm{Al}_{2} \mathrm{O}_{3}$ decresce com o aumento do índice, respondendo, respectivamente, ao aumento da quantidade de quartzo em detrimento dos minerais micáceos, recristalizados metamórficos da matriz de argilo-minerais dos protólitos. Nos diagramas, a população anômala (I) se destaca das demais amostras pelos conteúdos e pela variação de $\mathrm{SiO}_{2}$ e $\mathrm{Al}_{2} \mathrm{O}_{3}$, o que, comparando lâminas 
Tabela IX - indice de maturidade sedimentar empregando dados de análise química de tipos comuns de produtos residuais, sedimentos e rochas sedimentares, como publicados em Pettijohn (1975).

Table IX - Sedimentary maturity index using chemical data of common weathering residual products, sediments, and sedimentary rocks as published by Pettijohn (1975)

\begin{tabular}{|c|c|c|c|c|}
\hline Maverin & $\mathrm{SiO}_{3}$ & $\mathrm{Al}, \mathrm{O}_{3}$ & MAT & Pellifolon * \\
\hline Argila residual (bussalua) & 40.70 & 30,90 & 5694 & 78H8-MA \\
\hline Argila fon & $40.6 \mathrm{l}$ & {$[897$} & 6816 & $27088-4$ \\
\hline Argila grossis & 48.07 & 18.83 & 71.85 & $7708-4$ \\
\hline Argila nesidud (granivo) & 66.01 & 21.2] & 75.68 & $280 \mathrm{tat}-\mathrm{D}$ \\
\hline Media dt folbelhos & 58.10 & 15.40 & 79.04 & $274 t / 7 / A$ \\
\hline Folhetho carbonoso & 51.03 & 13.47 & $\mathbf{9 . 1 1}$ & 283A-9/A \\
\hline Grawtor & 60.51 & 15.36 & 79.73 & $228 / 7-9 / A$ \\
\hline Sile & 61.29 & 13.30 & 82.16 & $270 / 2-4$ \\
\hline Arobsio & 76.60 & 12.40 & o6.06 & $2167-5 \pi k$ \\
\hline Arein fina & 71.15 & 19.16 & 87.50 & $270 / 6-4$ \\
\hline Subarchisio & 92.13 & 4.42 & 95.42 & $2167-560$ \\
\hline Arenito proquintźtico & $92.9 \mathrm{~L}$ & 3.78 & 96.09 & $223 / 7-7 / E$ \\
\hline 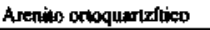 & 98.87 & $0.4 !$ & 99.58 & $2337-10 / A$ \\
\hline
\end{tabular}

delgadas de amostras das duas populações com IMAT semelhante, se manifesta por uma discreta diferença nas proporções de minerais micáceos.

Ao microscópio, ambas populações contêm, quartzo, clorita e/ou biotita, e uma mica branca. Na ausência de carbonato, as proporções de $\mathrm{CaO}$ da população II somente se justificam se a mica branca for uma margarita, o que é corroborado pela posição das amostras desse horizonte nas populações de baixo $\mathrm{Na}_{2} \mathrm{O}$ (parte da população II da Fig. 4d), baixo $\mathrm{K}_{2} \mathrm{O}$ (população III da Fig. 4e) e, também, baixo $\mathrm{Na}_{2} \mathrm{O}+\mathrm{K}_{2} \mathrm{O}$ (população II da Fig. 4f). As altas proporções de $\mathrm{Fe}_{2} \mathrm{O}_{3}, \mathrm{MgO}$ e $\mathrm{CaO}$ dessas amostras só se justificam se a matriz dos protólitos fosse uma mistura de argilo-minerais da família das esmectitas di- e tri-ocataédricas e vermiculita, com baixas proporções de illitas.

Nas figuras 4c, 4d, 4e e 4f, a maioria das amostras possuem proporções de $\mathrm{CaO}, \mathrm{Na}_{2} \mathrm{O}$ e $K_{2} \mathrm{O}$ que sugerem, na ausência ou raridade de plagioclásio, particularmente albita, que a mica branca consiste de amplas soluções sólidas entre sericita e paragonita. Em algumas amostras, a paragonita parece ser particularmente importante, como sugere a população I da figura $4 \mathrm{~d}$. Isto implica em que os protólitos deveriam ter uma matriz representada por uma mistura de argilo-minerais das famílias da illita e esmectita, em contraste com o horizonte anômalo.

$\mathrm{Na}$ figura $4 \mathrm{~g}$ as amostras se agrupam em três trends que, para um mesmo IMAT, diferem nas proporções de $\mathrm{Fe}_{2} \mathrm{O}_{3 \text { total }}$. O trend I é formado por 11 amostras, $65 \%$ das quais são xistos carbonosos e metafolhelhos com abundante clorita. O trend II reúne a maioria das amostras e inclui as do horizonte anômalo, as quais se agrupam ao longo da inflexão, junto com algumas amostras de outras posições estratigráficas, cujas proporções de $\mathrm{MgO}$ são maiores. Nos trends II e III, as lâminas delgadas de amostras com IMAT menor têm, em geral, uma razão clorita+biotita/mica branca em torno de $2: 1$, a qual inverte com o aumento do IMAT, sugerindo que a maturidade sedimentar influenciou a composição mineral da matriz.

$\mathrm{Na}$ figura $4 \mathrm{~h}$, a população I, que reúne a maioria das amostras, indica que, exceto por três acima e duas abaixo do principal agrupamento, o MgO médio não varia com o IMAT. Isto explica a presença de Fe-clorita como a variedade dominante nestas rochas, a qual contrasta com a Mg-clorita característica da população II, formada apenas por amostras do horizonte anômalo de Guarinos.
A variação de $\mathrm{TiO}_{2}$ com o IMAT (Fig. 4i) origina dois trends com gradientes distintos, cujas causas petrográficas não são perceptíveis em lâminas delgadas devido às proporções de ilmenita detrítica em geral inferiores a $1 \%$ nos metarenitos e à sua ausência nos demais litotipos. Ambos trends, negativos com IMAT, sugerem que a maior parte do oxido está contida nos minerais micáceos e não é uma fase importante da fração de minerais densos. Ademais, considerando a ausência de variação do $\mathrm{TiO}_{2}$ com IMAT da população II e que a mesma não é definida por um tipo específico de rocha nem uma posição estratigráfica definida, e que o Ti é relativamente imóvel no cliclo superficial, é provável que os dois trends correspondam a rochas que, na área-fonte, eram geoquimicamente distintas em relação ao Ti.

Raciocínio semelhante pode ser adotado para a variação do $\mathrm{P}_{2} \mathrm{O}_{5}$ (Fig. 4j). Apatita é rara a ausente nas amostras estudadas. Como resistato, esperar-se-ia que a variação do oxido fosse positiva com o IMAT. A sua variação negativa implica em incorporação nos minerais micáceos. Assim, os três trends provavelmente traduzem distintas disponibilidades de $\mathrm{P}_{2} \mathrm{O}_{5}$ durante os processos superficiais responsáveis pelas cargas detríticas que geraram os litotipos estudados.

Variações Recíprocas entre $\mathrm{CaO}, \mathrm{Na}_{2} \mathrm{O}$ e $\mathrm{K}_{2} \mathrm{O}$ A figura 5 a mostra que as rochas estudadas podem ser divididas em duas populações, exceto uma de xisto carbonoso rico em $\mathrm{Na}_{2} \mathrm{O}$ que se destaca nos três diagramas. Uma população contém a maioria das amostras, as quais originam um trend aproximadamente linear, de correlação positiva entre $\mathrm{CaO}$ e $\mathrm{Na}_{2} \mathrm{O}$, segundo uma razão aproximada de 1:1. Nesta, os metafolhelhos e xistos carbonosos são estatisticamente mais consistentes que os mais dispersos metarenitos. Outra têm proporções de $\mathrm{CaO}$ exponencialmente crescentes com $\mathrm{Na}_{2} \mathrm{O}$.

Ambas populações possuem amostras dos três litotipos, de diversas posições estratigráficas, indicando que os fatores litológico, estratigráfico e geográfico não foram decisivos na distribuição de $\mathrm{Ca}$ e Na. O predomínio de amostras com razões $\mathrm{Na}_{2} \mathrm{O}: \mathrm{CaO} \cong 1: 1$ e a ausência de controle geográfico e estratigráfico sobre a distribuição desses óxidos indicam que a pilha sedimentar foi preferencialmente formada por detritos com razões $\mathrm{Na} / \mathrm{Ca}$ homogêneas, eventualmente interrompidas por pulsos de cargas mais ricas em $\mathrm{Ca}$.

Por outro lado, a figura $5 \mathrm{~b}$ mostra que a maioria das amostras têm uma razão $\mathrm{K}_{2} \mathrm{O}: \mathrm{Na}_{2} \mathrm{O}>1$ e algumas com razão . Comparativamente às rochas equivalentes de outros terrenos arqueanos, este comportamento é anômalo, pois nestas a razão $\mathrm{K}_{2} \mathrm{O}: \mathrm{Na}_{2} \mathrm{O}$ é em geral $<1$, reflexo da composição estimada da área-fonte.

$\mathrm{Na}$ figura $5 \mathrm{c}$, as amostras se dispõem segundo um aumento progressivo de $\mathrm{K}_{2} \mathrm{O}$. Esta variação não traduz uma condição estratigráfica, pois tanto os xistos carbonosos basais de ambas faixas, quanto os metarenitos e metafolhelhos de topo distribuem-se ao longo de todo o espectro, sugerindo que os protólitos foram controlados por pulsos com razões Ca:Na:K variadas e aleatórias, se desconsideradas as modificações ocorridas durante a diagênese e metamorfismo.

Variação de Elementos Traços A figura 6 reúne os diagramas de variação de $\mathrm{Cr}, \mathrm{Ni}, \mathrm{Co}, \mathrm{V}, \mathrm{Sr}, \mathrm{Ba}, \mathrm{Zr}$ e Y com IMAT das amostras estudadas. A compreensão de certos aspectos da figura 6 requer as complementações contidas na figura 7. Exceto o $\mathrm{Sr}$, a consistência geoquímica dos óxidos de elementos maiores com IMAT também ocorre com os elementos traços. Assim como os óxidos de elementos maiores, os elementos traços também não discriminam os litotipos.

Os teores de $\mathrm{Cr}$ (Figs. 6a) decrescem com IMAT em duas populações, ambos indicando que a concentração do elemento cresce com as proporções de minerais micáceos e não com 

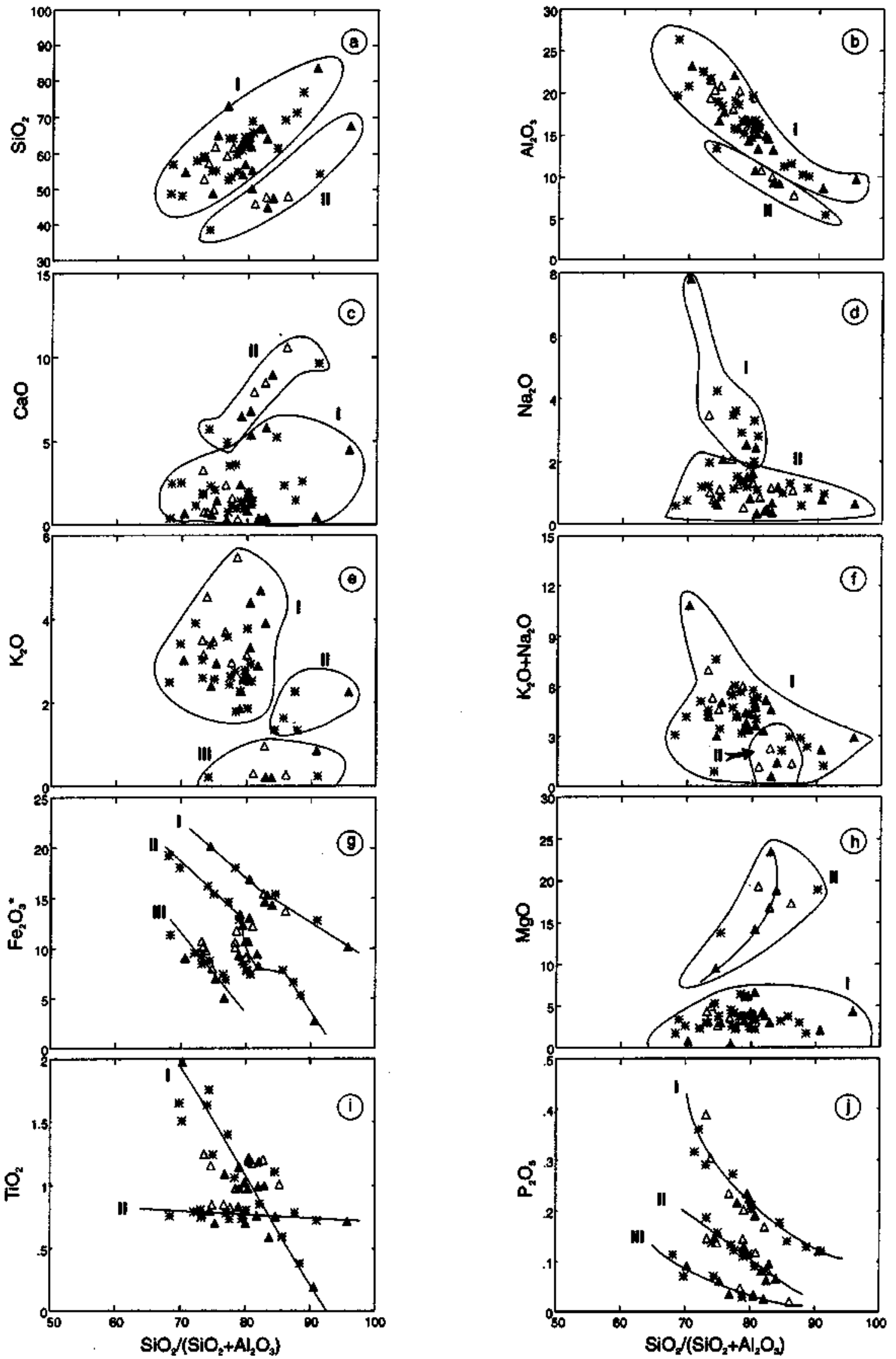

Figura 4 - Diagramas de variação dos óxidos de elementos maiores das rochas metassedimentares detríticas dos greenstone belts de Crixás e Guarinos com o índice geoquímico empírico de maturidade sedimentar detrítica. Símbolos: triângulos cheios - xistos carbonosos, triângulos vazados $=$ metafolhelhos, $*=$ metarenitos.

Figure 4 - Variation of major element oxides of the detrital metasedimentary rocks of the Crixás and Guarinos greenstone belts with the empirical geochemical maturity index of detrital sedimente. Symbols: filled triangle $=$ carbonaceous schist; open triangle $=$ metashales; $*=$ metarenites. 

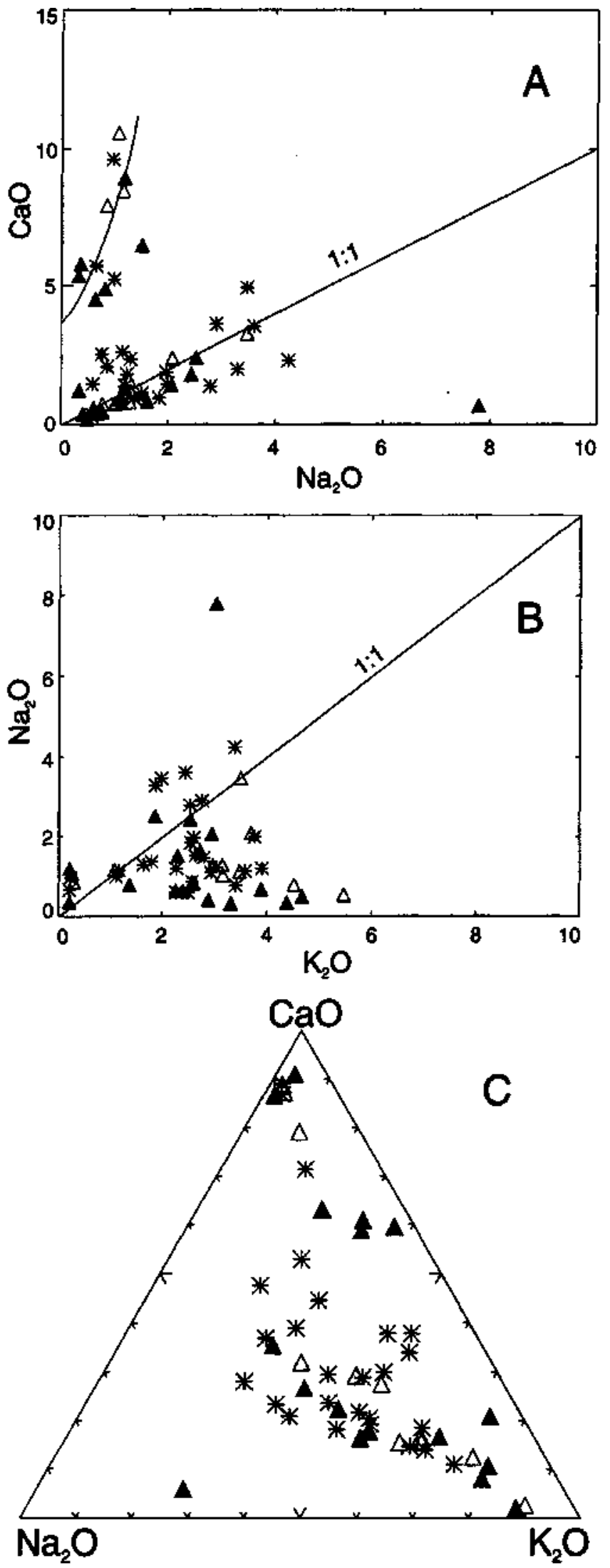

Figura 5 - Variações recíprocas entre $\mathrm{CaO}, \mathrm{Na}_{2} \mathrm{O}$ e $\mathrm{K}_{2} \mathrm{O}$ das rochas metassedimentares detríticas dos greenstone belts de Crixás e Guarinos, Símbolos como na figura 4. Figure 5 - Reciprocal variation of $\mathrm{CaO}, \mathrm{Na}_{2} \mathrm{O}$, and $\mathrm{K}_{2} \mathrm{O}$ of the detrital metasedimentary rocks of the Crixás and Guarinos greenstone belts. Symbols as in figure 4 .
Cr-espinélios resistatos. Como já evidenciado pela Tabela VIII, Cr e Ni discriminam bem as amostras do horizonte anômalo de Guarinos (população I das Figs. 6a e 6b) dos demais horizontes (população II). A variação de $\mathrm{Cr}$ com o Ni (Fig. 8a) repete as duas populações e acrescenta fatos novos. Primeiro, que ambas se alinham aproximadamente segundo o trend ígneo. Segundo, a razão Cr:Ni média de basaltos toleiíticos está embutida na população I e a do manto primitivo no da população II. Estes dois aspectos indicam que a razão $\mathrm{Cr}: \mathrm{Ni}$ de rochas ígneas é transferida, sem desvios significativos, para o ciclo superficial, devido à relativa imobilidade de ambos. Terceiro, e talvez o mais significativo, pela primeira vez é possível distinguir, ainda que discretamente, os litótipos. Assim, os metarenitos são mais pobres em Ni que os metafolhelhos, por sua vez mais pobres que os xistos carbonosos, independente dos teores de Cr. No par metarenito/metafolhelho dos turbiditos, o comportamento do Ni indica a sua retenção em argilo-minerais, comum no intemperismo de rochas ultramáficas. A ausência de Cr-espinélios detríticos nas amostras estudadas implica, por outro lado, que as razões Cr:Ni dos argilo-minerais dos protólitos, hoje micas, não foram significativamente modificadas em relação à área-fonte e sugerem que a mesma continha um apreciável volume de rochas máficas e ultramáficas.

Os teores de Co e V (Figs. 6c e 6d) e sua variação com IMAT também se distribuem em duas populações. Os teores de Co da população I, apesar da dispersão, aparentemente crescem com IMAT, enquanto os do V decrescem. Nenhum trend é gerado pelas amostras das populações II. À primeira vista, as populações I e II parecem ser as respectivas recíprocas. Contudo, a figura $7 \mathrm{~b}$ indica que a variação de Co independeu do $\mathrm{V}$ durante a história sedimentar das rochas estudadas, contrastando com a correlação positiva entre ambos no ciclo ígneo e sugindo que estes elementos se divorciaram no ciclo superficial.

A estas observações se acresce, primeiro, que ambos grupos contêm amostras de Crixás e Guarinos, carecendo, portanto, de controle geográfico e, segundo, que amostras com altos e baixos teores de Co e/ou V se alternam em horizontes de espessura variada nos xistos carbonosos basais e nos metaturbiditos de topo, implicando em ausência de controle estratigráfico. A variação pode, pois, ser explicada por flutuações na organização da composição dos detritos na fonte. Os teores de $\mathrm{Sr}$ se dispersam com IMAT (Fig. 6e). Contudo, a correlação $\mathrm{CaOxSr}$ (Fig. 7c) é linear e positiva e mais íngreme que nas rochas ígneas, sugerindo que parte do $\mathrm{Sr}$ perdeu-se no ciclo sedimentar. Por outro lado, a figura 7c também mostra dois trends, dentre os quais o de alto-CaO é formado pelas 8 amostras do horizonte anômalo de Guarinos e quatro de xisto carbonoso, sendo duas de afloramentos em Guarinos e duas, com os mais baixos teores de Sr, de Crixás. Curiosamente, as duas últimas não se agrupam com as anômalas nos demais diagramas.

A variação do Ba (Fig. 6f) é dispersa, mas ressalta as amostras do horizonte anômalo de Guarinos pelos baixos teores. Contudo, a correlação SrxBa (Fig. 8d) além de destacar o horizonte anômalo (população III) e ser positiva em duas das três populações, permite, mais eficazmente que na correlação CrxNi, distinguir os litótipos entre si. Assim, todas as amostras de xisto carbonoso e duas de metafolhelho delineiam um estreito campo de teores mais elevados em $\mathrm{Ba}$ (população I), que contrasta com os metarenitos e alguns metafolhelhos (população II), de teores menores. Isto sugere que o ambiente anóxico foi mais propício à concentração de $\mathrm{Ba}$ que o turbidítico, talvez em razão de eventuais exalações durante $o$ vulcanismo básico penecontemporâneo. Entretanto, a correlação positiva entre ambos e entre $\mathrm{Sr}$ e $\mathrm{Ca}$ indicam que estes elementos também estiveram geneticamente interligados no ciclo superficial. Isto sinalisa que os protólitos dos xistos 

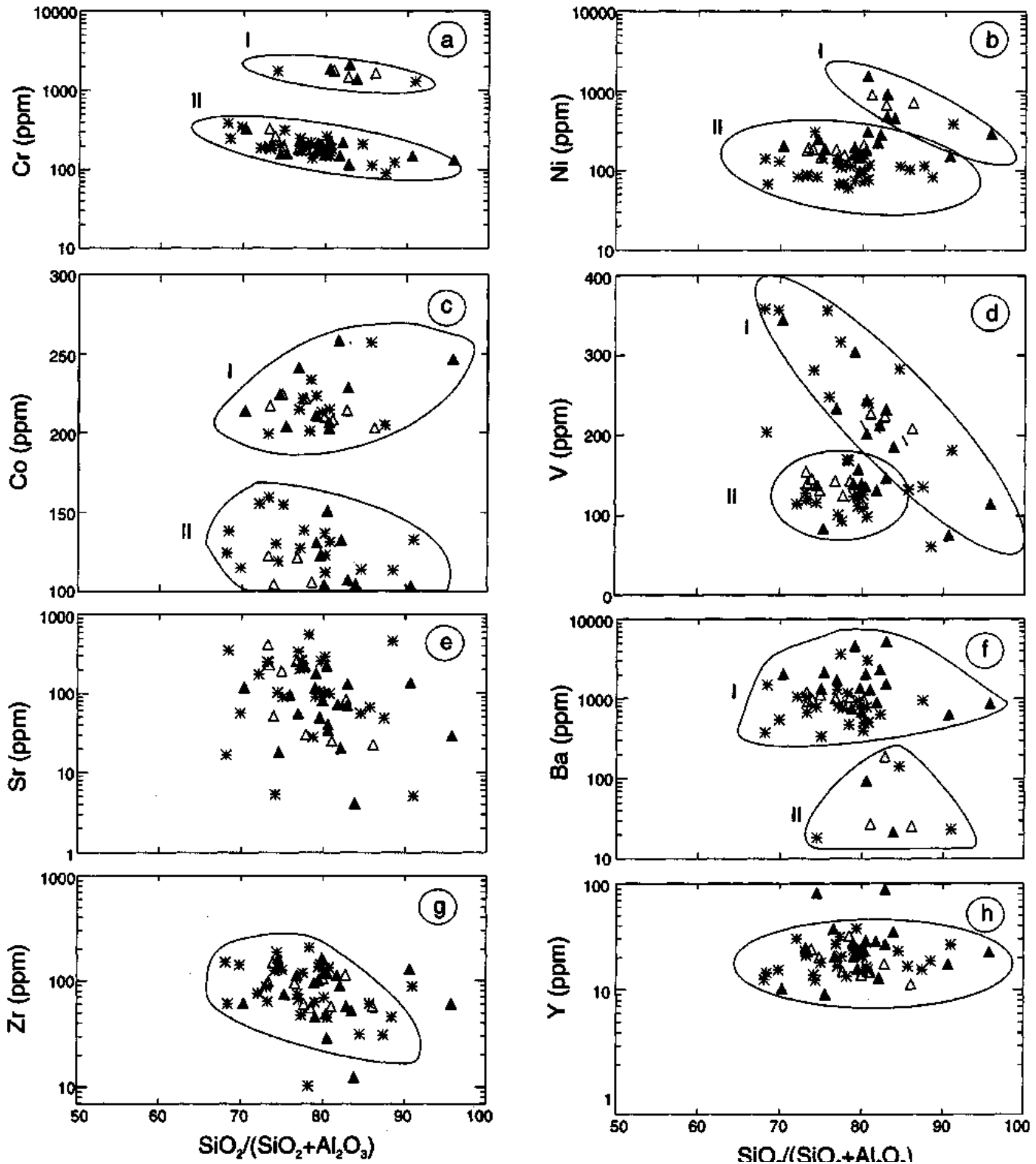

Figura 6 - Diagramas de variação dos elementos traços das rochas metassedimentares detríticas dos greenstone belts de Crixás e Guarinos com o índice geoquímico empírico de maturidade sedimentar detrítica. Símbolos: triângulos cheios $=x i s t o s$ carbonosos, triângulos vazados $=$ metafolhelhos, $*=$ metarenitos.

Figure 6 - Variation of trace elements of the detrital metassedimentary rocks of the Crixás and Guarinos greenstone belts with an empirical geochemical maturity index of detrital sediments. Symbols: filled triangle $=$ carbonaceous schist; open triangle $=$ metashales; $*$ = metarenites.

carbonosos formaram-se, provavelmente pela convergência de mais de um processo.

Os teores de $\mathrm{Zr}$ (Fig. 6g), exceto por 5 amostras mais dispersas, decrescem com o IMAT, indicando que o elemento é progressivamente menos importante com a maturidade $\mathrm{Zr}$ dos protólitos. A raridade ou ausência de zircão nestas rochas sugere que o elemento está adsorvido em minerais micáceos, permitindo interpretá-lo, pela sua imobilidade, como uma herança geoquímica da área-fonte. Já o Y, apesar da dispersão, é invariável com IMAT (Fig. 6h) e com o Zr (Fig. 7e).

Elementos Terras Raras As Tabelas V e VI mostram que cerca de $50 \%$ das amostras contêm um $\sum$ ETR entre 20 e 100 ppm, compatível com o observado por Taylor \& McLennan (1985) em metassedimentos arqueanos e grauvacas fanerozóicas pobres em quartzo. Cerca de $40 \%$ das amostras 

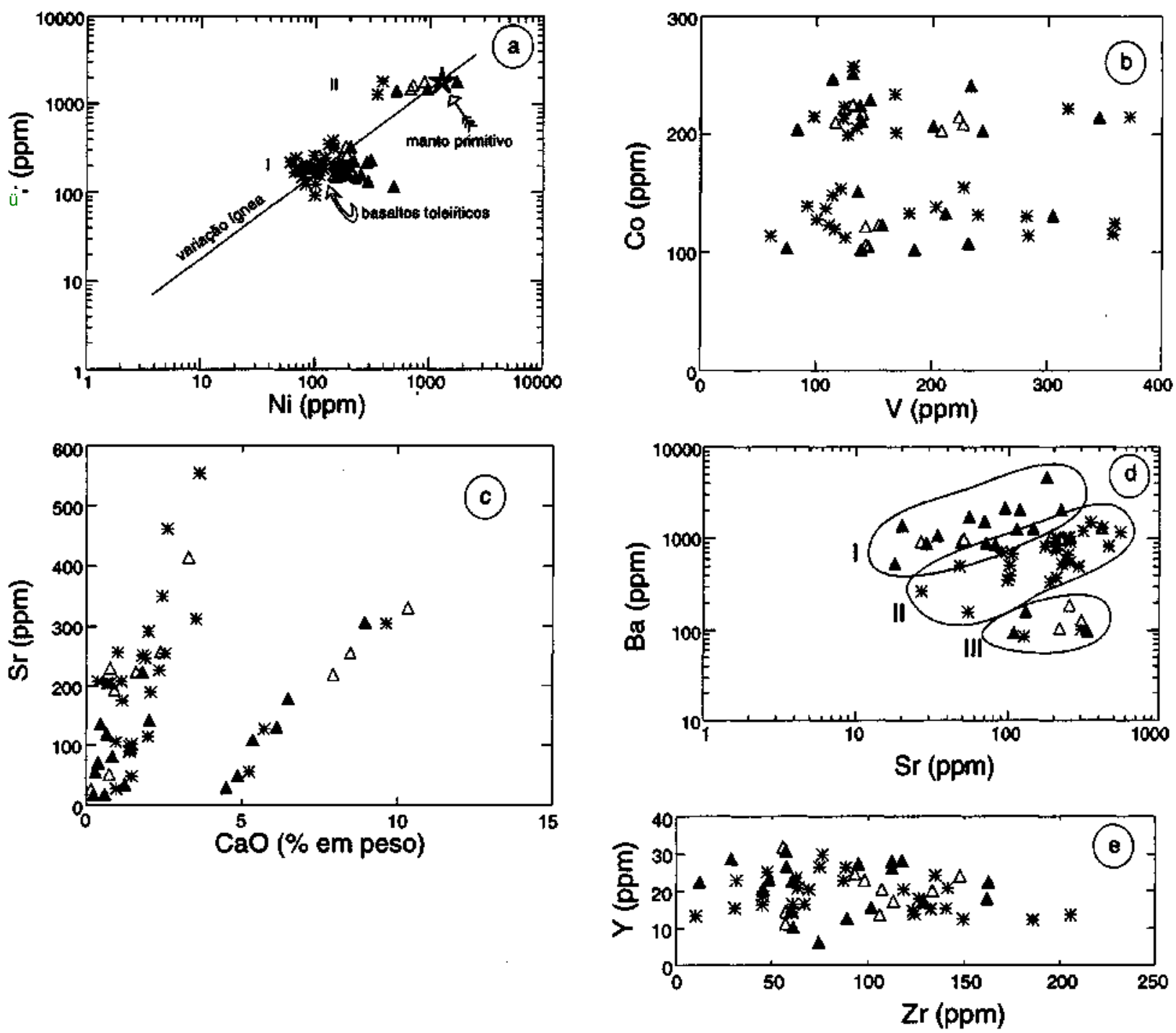

Figura 7 - Diagramas de correlação (a) Nix Cr, (b) Vx Co, (c) CaO x Sr, (d) Sr x Ba, and (e) Zrxy das rochas metassedimentares detriticas dos greenstone belts de Crixas e Guarinos. Símbolos como na figura 4.

Figure 7 - (a) $\mathrm{Ni}$ x Cr, (b) $\mathrm{V}$ x Co, (c) $\mathrm{CaO}$ x Sr, (d) $\mathrm{Sr}$ x Ba, and (e) $\mathrm{Zr}$ x Y correlation diagrams of the Crixas and Guarinos greenstone belt detrital metassedimentary rocks. Symbols as in figure 4 .

possuem entre 100 e 200 ppm e $10 \%$ entre 200 e 300 ppm, teores típicos de grauvacas fanerozóicas ricas a intermediárias em quartzo.

Os três litotipos do horizonte anômalo de Guarinos possuem os mais baixos valores de $\Sigma$ ETR, situados entre 27 e 60 ppm, em contraste com os demais horizontes estratigráficos. Exceto nesse horizonte, teores entre 100 e 200 ppm oscilam em torno do background(112 ppm) e o intervalo de 200 a 300 ppm contém as concentrações anômalas, normalmente situadas em metarenitos.

Os ETR normalizados ao North American Sediment Composite - NASC (Fig. 8) evidencia que as rochas estudadas contrastam com as equivalentes pós-arqueanas pelas baixas abundâncias relativas em ETRL e presença de anomalias positivas de Eu. Os ETRP têm distribuição em geral plana. A abundância maior de ETR's ocorre nos xistos carbonosos, é menor nos metargilitos e tem ampla flutuação nos metarenitos. Destaca-se, novamente, o horizonte anômalo, onde há um fracionamento de ETRL inferior a 1, não observado nos demais horizontes.
ENSAIO DE PROVENIÊNCIA A comparação da abundância média (Fig. 9a) dos elementos analisados nas rochas estudadas, calculada a partir da Tabela VIII, e suas equivalentes pós-arqueanas (NASC) revela que (1) $\mathrm{SiO}_{2}$ e $\mathrm{Al}_{2} \mathrm{O}_{3}$ ocorrem em proporções idênticas em ambos grupos de rochas; (2) as amostras estudadas são mais ricas em $\mathrm{Fe}_{2} \mathrm{O}_{3}$ *, $\mathrm{CaO}, \mathrm{MgO}, \mathrm{MnO}, \mathrm{Ba}, \mathrm{Cr}, \mathrm{Ni}, \mathrm{Co}, \mathrm{V}$ e Sc, típicos de filiação máfico-ultramáfica, e mais pobres nos demais, consangüineos com rochas intermediárias e félsicas; (3) os ETRL estão mais concentrados em rochas pós-arqueanas, mas Eu é ligeiramente mais abundante nas rochas estudadas e Tb e Lu (ETRP) ocorrem em proporções similares em ambas. Isto sugere que a composição da área-fonte dos protólitos das rochas de Crixas e Guarinos foi distinta daquela estimada para os sedimentos pós-arqueanos em geral.

Apesar da abundância dos óxidos de elementos maiores de sedimentos elásticos ser um argumento frágil para definir os atributos químicos da área-fonte, as proporções combinadas de $\mathrm{Fe}_{2} \mathrm{O}_{3}, \mathrm{CaO}, \mathrm{MgO}, \mathrm{MnO}, \mathrm{Cr}, \mathrm{Ni}, \mathrm{Co}$, Sc e os baixos teores de ETRL relativamente aos ETRP apontam que a proveniência das rochas estudadas é máfico-ultramáfica. Por outro lado, a variação dos teores de Th, La e Sc (Fig. 9b) das 


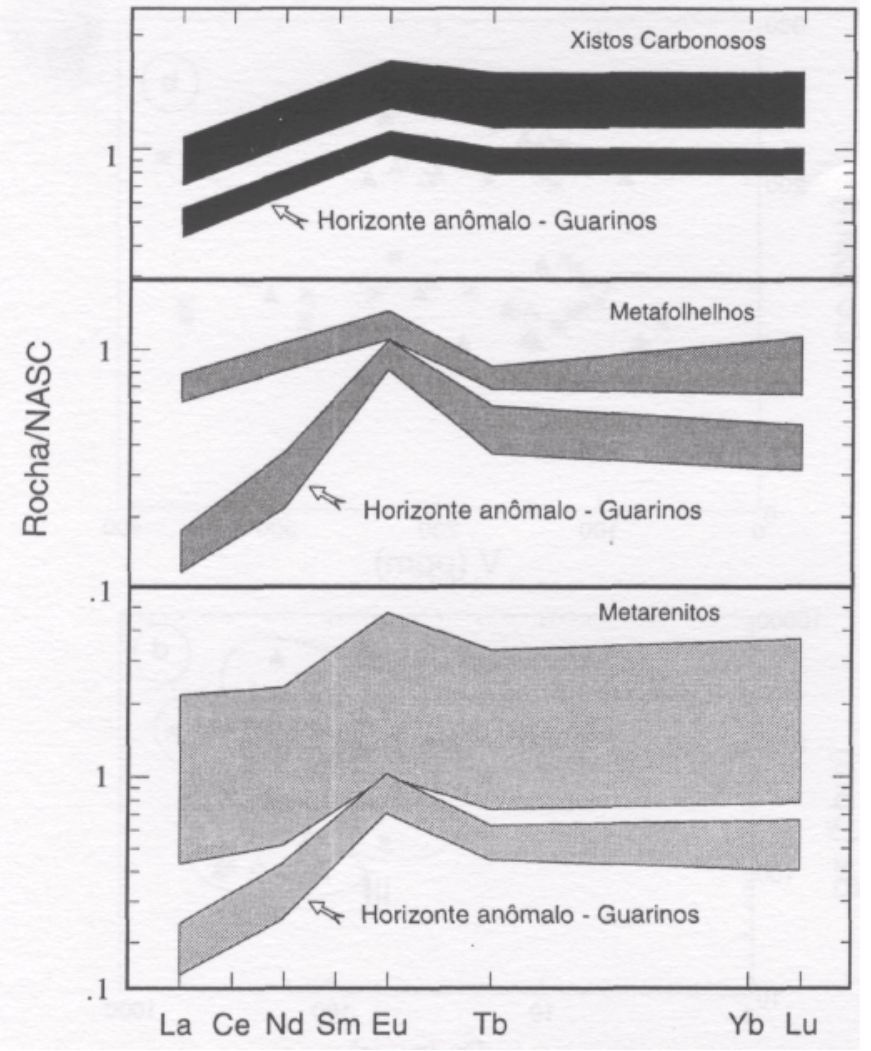

Figura 8 - Assinaturas dos Elementos Terras Raras (ETR) normalizados ao NASC de xistos carbonosos, metafolhelhos e metarenitos dos greenstone belts de Crixás e Guarinos. Dados do NASC segundo Gromet et al. 1984. Figure 8 - NASC normalized REE signatures of carbonaceous schists, metashales and metarenites of the Crixás and Guarinos greenstone belts. NASC data according to Gromet et al. 1984.

amostras onde foram determinados, segue um trend linear, a partir do vértice do Sc, rumo ao campo restrito das rochas sedimentares pós-arqueanas, indicando uma contribuição também de rochas félsicas e, assim, de proveniência bimodal.

Para modelar esta proveniência bimodal, empregamos elementos com as seguintes propriedades: (1) relativa imobilidade, (2) capacidade quantitativa e física de transporte na forma adsorvida em argilo-minerais, (3) invariância ou correlação negativa com IMAT, e (4) propriedades geoquímicas opostas. Dentre todos os elementos, os que cumprem estas propriedades são, aos pares, $\mathrm{Zr}$-Y e Cr-Ti. Para modelar a proveniência, empregamos as suas razões, no pressuposto de que estas, e não os seus teores, são mais sensíveis às características da área-fonte (Fig. 9c).

A figura 9c inclui, também, as razões $\mathrm{Cr} / \mathrm{Ti}$ e $\mathrm{Zr} / \mathrm{Y}$ de uma amostra de metabasalto e uma de metakomatiito do greenstone belt de Guarinos. Para compatibilizar a ausência de anomalias negativas de $\mathrm{Eu}$, a presença, ainda que rara, de plagioclásio e a ausência de feldspato potássico nas rochas estudadas, o diagrama também inclui uma amostra de um tonalito que intrude, no oeste, o greenstone belt de Guarinos (Tonalito Tocambira).

A variação das razões $\mathrm{Cr} / \mathrm{Ti}$ e $\mathrm{Zr} / \mathrm{Y}$ mostra que a maioria das amostras pode ser explicada por uma área-fonte dominada por rochas básicas, e que o horizonte anômalo de Guarinos requer uma participação maior de komatiitos, subordinadamente basaltos. Ambos, no entanto, mostram um aumento da razão $\mathrm{Zr} / Y$ que implica na participação de proporções variadas de uma proveniência menor também de rochas félsicas e, por conseguinte, bimodal.
DISCUSSÃO Do exposto se conclui que as propriedades geoquímicas das seções metassedimentares estudadas não diferem das obtidas por Feng \& Kerrich (1990, Camiré et al (1993), Mueller et al. (1994), Wronkiewicz \& Condie (1987), Nancy \& Taylor (1976), Maas \& McCulloch (1991), Jenner et al. (1981), Gibbs et al. (1986), Naqvi et al.(1988) e Arora et al (1994) em terrenos arqueanos de outras regiões. Por outro lado, essas propriedades, agora mais abundantes, também corroboram as observações preliminares anteriores de Jost et al. $(1993,1995)$ e sustentam as suas aplicações estratigráficas e de mapeamento sugeridas por Jost (1996).

Os xistos carbonosos basais e os metaturbiditos distais de topo de ambas faixas traduzem regimes tectônicos contrastantes. O progressivo ingresso do ambiente anóxico por declínio gradativo do vulcanismo basáltico e as intercalações, ainda que eventuais, de metabasaltos em várias posições estratigráficas dos xistos carbonosos indicam a bacia deposiconal esteve sob regime distensivo. Já os metaturbiditos, pela sua natureza e súbito ingresso na bacia, podem ser interpretados como produto de uma fase de soerguimento acelerado. Contudo, a semelhança geoquímica entre os xistos carbonosos e os metaturbiditos indica que a variação no regime tectônico não foi acompanhada de mudanças na composição da áreafonte dos dois segmentos estratigráficos.

A interpretação da composição de áreas-fonte com base nas características geoquímicas dessas rochas detríticas não significa atribuir-lhes uma proveniência continental. Se assim fosse, isto implicaria em solucionar, para a área, pelo menos dois aspectos.

Primeiro, especular, para a região, sobre a presença de um continente arqueano. Até o presente, são desconhecidas, em base geocronológica, rochas mais antigas que $2.8 \mathrm{Ga}$. (Tassinari \& Montalvão 1980, Montalvão 1985, Arndt et al. 1989) a provável idade das rochas supracrustais e dos terrenos granito-gnáissicos. Isto contrasta com o grau de certeza sobre a existência e a composição dos continentes que alimentaram bacias sedimentares intra- e pericratônicas mais jovens que $2.5 \mathrm{Ga}$ e sobre a proveniência elástica.

Segundo, que os pelitos de terrenos com vulcanismo ativo, tais como arcos de ilha e greenstone belts, não fornecem muitas informações acerca das crostas continentais contemporâneas (Gromet et al. 1984, Taylor \& McLennan 1985, Gibbs et al. 1986). Ademais, as suas características geológicas diferem, significativamente, de bacias intracratônicas e margens continentais passivas, cujos detritos elásticos provém diretamente dos continentes adjacentes.

$\mathrm{Na}$ área estudada, estes aspectos podem ser conciliados se a proveniência for interpretada como o fruto, em grande parte, da erosão e mistura de produtos de intemperismo de vulcânicas máfico/ultrmáficas das seções estratigráficas inferiores. Assim, os protólitos dos xistos carbonosos podem ter sido depositados em amplas depressões da topografia da superfície dos basaltos e alimentados a partir das áreas altas. Já a deposição turbidítica, vinculada ao soerguimento da área-fonte, também requer erosão da pilha vulcânica máfico/ultramáficaa, mas com incisão insuficiente para alcançar os komatiitos basais. A fraca contribuição ultramáfica pode ser explicada pela erosão de escassos basaltos komatíticos intercalados nos basaltos, exceto o horizonte anômalo de Guarinos, cujas rochas metassedimentares se explicam por erosão parcial das rochas ultramáficas associadas, a exemplo de Piumhi (Lima 1996).

A contribuição félsica é, ainda, problemática. Nos xistos carbonosos, os níveis de púmice trondhjemítico (Theodoro 1995) é, até o presente, a única evidência direta de rochas félsicas geoquimicamente compatíveis as metassedimentares, e indica que esta componente pode provir de cinza ejetada de edifícios vulcânicos distais. Nos metaturbiditos, a contribuição félsica poderia ser explicada por soerguimento, por 


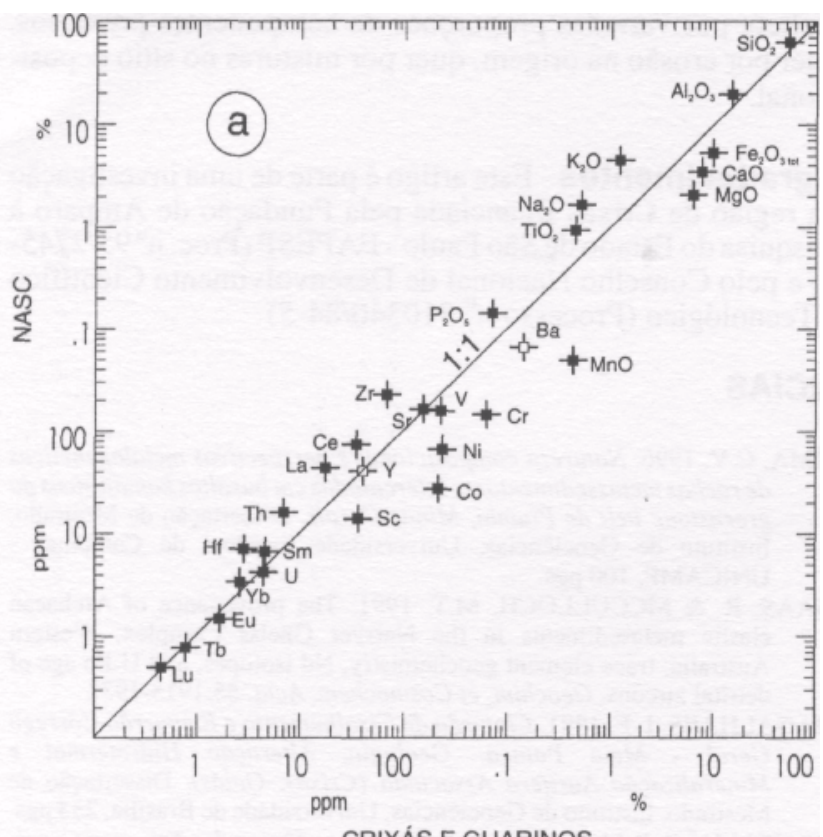

CRIXÁS E GUARINOS
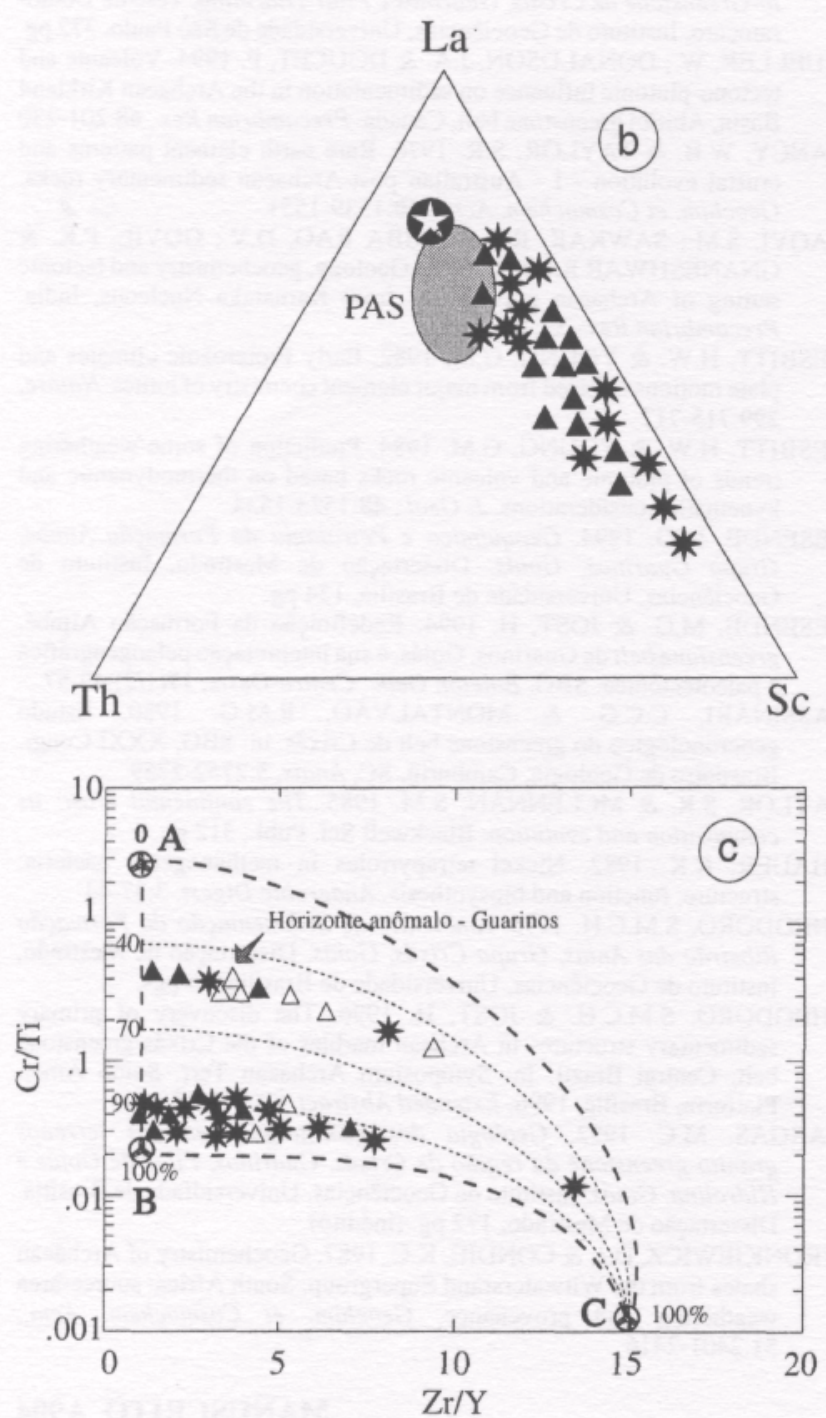

Figura 9-(a)- Comparação da composição média das rochas metassedimentares detríticas dos greenstone belts de Crixás e Guarinos com a de folhelho de referência pós-arqueano (NASC). Observar que as rochas estudadas são mais ricas em elementos ferromagnesianos e mais pobres nos demais, comparativamente às equi-valentes pós-arqueanas. (b) - Diagrama Th-La-Sc mostrando a posição das amostras de rochas metassedimentares detriticas estudadas, comparativamente ao restrito campo de equivalentes pós-arqueanas (PAS) e a da razão média granodiorítica da crosta continental (estrela), ambos segundo Taylor \& McLennan (1985). (c) Modelo bimodal a composição das rochas metassedimentares detriticas dos greenstone belts de Crixás e Guarinos. Os pontos $A$ e $B$ correspondem às razões $\mathrm{Zr} / \mathrm{Y}$ e Cr/Ti de uma amostra de komatiito e uma de metaba-salto das porções estratigráficas inferiores do greenstone belt de Guarinos. $O$ ponto $C$ representa as razões de um tonalito intrusivo em ambas faixas (Tonalito Tocambira). As linhas tracejadas e pontilhadas correspondem a misturas de diferentes proporções de komatiito e basalto (adaptado de Camiré et al. 1993). Símbolos como no figura 4.

Figure 9 - (a) - Diagram comparing the average composition of the detrital metasedimentary rocks of the Crixás and Guarinos greenstone belts and the post-Archean North American Sediment Composite (NASC). Observe that, in the average, the studied rocks are richer and ferromagnesian elements and poorer in other elements. (b) -Th-La-Sc diagram showing the linear array of the detrital metassedimentary rocks of the Crixás and Guarinos greenstone belts, as well as the restrict field of the post-Archaean shales (PAS) and of the granodioritic average continental crust (star), both after Taylor \& McLennan (1985). (c) - Bimodal mixture modeling of the source área of the Crixás and Guarinos metassedimentary rocks. Points A and B correspond to the $\mathrm{Zr} / \mathrm{Y}$ and $\mathrm{Cr} / \mathrm{Ti}$ ratios of one sample of metakomatiite and one of metabasalt of the lower stratigraphic sections of the Guarinos belt, and point $\mathrm{C}$ the ratios of one sample of as Archaean tonalite (Tocambira Tonalite) intruded in both belts. Doted and traced lines represent mixing lines of metakomatiite and metabasalt (adapted from Camiré et al. 1993).

diapirismo, das unidades vulcânicas inferiores e subseqüente exposição de núcleos tonalíticos.

Contudo, Jost et al. (1995) e Jost \& Queiroz (1995) mostram que (1) as relíquias de estruturas primárias indicativas de topo-e-base em rochas metavulcânicas e metassedimentares de ambas faixas indicam que os níveis estratigráficos mais jovens, sedimentares, estão estruturalmente sotopostos aos mais velhos, vulcânicos, e, por conseguinte, as seqüências estratigráficas estão completamente invertidas, e (2) o soerguimento diapírico de gnaisses e intrusões tonalítico-granodioríticos adjacentes, e sua exposição na superfície, ocorreu após o metamorfismo, deformação, transporte tectônico e inversão estratigráfica das supracrustais. Isto exclui os complexos tonalítico-granodioríticos regionais da área-fonte félsica das rochas estudadas. A isto se acresce o predomínio, em área, de gnaisses granodioríticos, cujas anomalias negativas de Eu (Vargas 1992) não sustentam, na mistura bimodal de detritos, as anomalias positivas das amostras estudadas.

Os níveis de xisto carbonoso com fragmentos de pumice trondhjemítico são, até o momento, as únicas evidências diretas de atividade magmática félsica contemporânea e geoquímicamente compatível com as rochas metassedimentares estudadas. A semelhança mineralógica entre vulcanoclásticas trondhjemíticas e os metaturbiditos pode estar dificultando o sua identificação em meio aos metaturbiditos, dificuldade esta que se acentua na medida em que as primeiras tivessem o calibre de cinza. O comportamento similar dos elementos traços indica que a componente félsica de ambas seções estratigráficas não mudou com o regime tectônico. Assim, enquanto nos xistos carbonosos ela se explica por vulcanismo 
ativo, nos metaturbiditos ela pode ser explicada por erosão dos respectivos edifícios durante o soerguimento.

Por fim, o comportamento geral de óxidos de elementos maiores e menores e o dos elementos traços permite concluir que os sítios de deposição em ambos regimes tectônicos foram alimentados por cargas de composição variada. As flutuações da abundância de elementos imóveis entre as amostras indicam variação nas proporções dos componentes primários. Isto, combinado com a ausência de uma variação secular daquelas abundâncias ao longo das seções sedimentares es- tudadas, sugere que a carga elástica foi composta, de modo cíclico, por variadas proporções de componentes primários, quer por erosão na origem, quer por misturas no sítio deposicional.

Agradecimentos - Este artigo é parte de uma investigação na região de Crixás financiada pela Fundação de Amparo à Pesquisa do Estado de São Paulo - FAPESP (Proc. n ${ }^{\circ}$ 95/27453) e pelo Conselho Nacional de Desenvolvimento Científico e Tecnológico (Processo n $310340 / 84-5$ )

\section{REFERENNCIAS}

ARNDT, N.T.; TEIXEIRA, N.A. \& WHITE, W.M. 1989. Bizarre geochemistry of komatiites from the Crixás greenstone belts, Brazil. Contrib. Mineral. Petrol, 101:187-197.

ARORA, M.; KHAN, R.M.K. \& NAQVI, S.M. 1994. Composition of the middle and late Archean upper continental crust as sampled from the Kaldurga Conglomerate, Dharwar craton, índia. Precambrian Res., 70:93-112

BARWISE, A.J.G. \& WHITEHEAD, E.V. 1984. Review: abundance and origin of fossil fuel metais. In: S.S. Augustithis (edit) The Significance of Trace Elements in Solving Petrogenetic Problems and Controversies. Theoprastus Publications S.A., Atenas, Grécia, pg. 599-643

CAMIRÉ, G.E.; LAFLÈCHE, M.R. \& LUDDEN, J.N. 1993. Archaean metasedimentary rocks from the northwestern Pontiac Subprovince of the Canadian Shield: chemical characterization, weathering and modelling of the source áreas. Precambrian Res., 62:285-305

COX, R.; LOWE, D.R. \& CULLERS, R.L. 1995. The influence of sediment recycling and basement composition on evolution of mudrock chemistry in the south-westrern United States. Geochim. Cosmoch. Âcta, 59:2919-2940

FENG, R. \& KERRICH, R. 1990. Geochemistry of fme-grained clastic sediments in the Archaean Abitibi greenstone belt, Canada: Implications for provenance and tectonic setting. Geochim. Cosmochim. Acta, 54:1061-1081.

FORTES, P.T.F.O \& TAKAKI, T. 1993. Estudo dos isótopos de carbono e oxigênio em rochas encaixantes do depósito aurífero Mina III, Crixás, Goiás. IV Congr. Brasileiro de Geoquímica, Resumos Expandidos, pg.:186-188

FORTES, P.T.F.O. 1995. Metalogenia dos Depósitos Auríferos Mina III, Mina Nova e Mina Inglesa, Greenstone Belt de Crixás, Goiás. Tese de Doutoramento, Instituto de Geociências, Universidade de Brasília, 207 Pgs.

GIBBS, A.K.; MONTGOMERY, C.W.; O'DAY, P.A. \& ERSLEV, E.A. 1986. The Archaean-proterozoic transition: evidence from the geochemistry of metasedimentary rocks of Guyana and Montana. Geochem. et Cosmochem. Acta, 30:2125-214

GROMET, L.P.; DYMEK, R.F.; HASKIN, L.A. \& KOROTEV, R.L. 1984 The "North American shale composite": Its compilation, major and trace element characteristics. Geochim. et Cosmochem. Acta. 48:2469-2482

JENNER, G.A.; FRYER, B.J. \& MCLENNAN, S.M. 1981. Geochemistry of the Archaean Yellowknife Supergroup. Geochim. et Cosmochem. Acta., 45:1111-1129-

JOST, H. 1996. Are the detrital metasedimentary rocks of the Crixás and Gurainos greenstone belts, Goiás, of the same age and provenance? aConstraints from REE geochemistry. SBG, Symposium Archean Terranes of the South American Platform, Extended Abstracts volume, pg. 21-25.

JOST, H.; FIGUEIREDO, A.M.G. \& FERREIRA, A.V. 1995. Elementos em traço e a proveniência elástica na transição de ambiente euxênico para turbidítico em metassedimentos do greenstone belt de Guarinos, Goiás. In SBGq.V Congressp Brasileiro de Geoquímica, Niterói, Anais em CD-ROM.... 1995,4 pgs.

JOST, H.; KUYUMJIAN, R.M. e SILVA, C.A. _ 1993 _ Caracteríticas geoquímicas e a proveniência dos metassedimentos arqueanos do Grupo Guarinos, GO. Soc. Bras. Geoqu., IV Congresso Brasileiro de Geoquímica, Brasília, Anais em CD-ROM, pg. 109-112

KAPO, G. 1978. Vanadium: key to Venezuelan fossil hydrocarbons. In: G.V. Chilingarin \& T.F. Yen (edit.) Bitumens, Asphalts and Tar Sands. Elsevier Scient. Publ. Co, New York, p.: 213-241.

LANCASTER, J.R. 1982. New biological paramagnetic centre: octahedrally coordinated nickel in the methanogenic bactéria. Science, 216:1324-1325
LIMA, C.V. 1996. Natureza composicional e perspectivas metalogenéticas de rochas metassedimentares intercaladas em basaltos komatiíticos do greenstone belt de Piumhi, Minas Gerais. Dissertação de Mestrado, Instituto de Geociências, Universidade Estadual de Campinas UNICAMP, 100 pgs.

MAAS, R. \& MCCULLOCH, M.T. 1991. The provenance of Archaean clastic metasediments in the Narryer Gneiss Complex, Western Austrália: trace element geochemistry, $\mathrm{Nd}$ isotopes, and $\mathrm{U}-\mathrm{Pb}$ age of detrital zircons. Geochim. et Cosmochem. Acta 55:1915-1932

MAGALHÃES, L.F. 1991. Cinturão de Cisalhamento e Empurrão Córrego Geral - Meia P ataca: Geologia, Alteração Hidrotermal e Mineralização Aurífera Associada (Crixás, Goiás). Dissertação de Mestrado, Instituto de Geociências, Universidade de Brasília, 233 pgs.

MONTALVÃO, R.M.G. 1985. Evolução Geotectônica dos Terrenos Granito-Greenstone de Crixás, Guarinos e Pilar-Hidrolina. Tese de Doutoramento, Instituto de Geociências, Universidade de São Paulo, 372 pg.

MUELLER, W.; DONALDSON, J.A. \& DOUCET, P. 1994. Volcanic and tectono-plutonic influence on sedimentation in the Archaean Kirkland Basin, Abitibi greenstone belt, Canada. Precambrian Res., 68:201-230

NANCY, W.B. \& TAYLOR, S.R. 1976. Rare earth element patterns and crustal evolution - I - Australian post-Archaean sedimentary rocks. Geochim. et Cosmochem. Acta., 40:1539-1551

NAQVI, S.M.; SAWKAR, R.H.; SUBBA RAO, D.V.; GOVIL, P.K. \& GNANESHWAR RAO, T. 1988. Geology, geochemistry and tectonic setting of Archaean graywackes from Karnataka Nucleous, índia. Precambrian Res., 39:193-216

NESBITT, H.W. \& YOUNG, G.M. 1982. Early Proterozoic climates and plate motions inferred from major element chemistry of lutites. Nature, 299:715-717

NESBITT, H.W. \& YOUNG, G.M. 1984. Prediction of some weathering trends of plutonic and volcanic rocks based on thermodynamic and kynematic considerations. J. Geol., 48:1523-1534

RESENDE, M.G. 1994. Geoquímica e Petrologia da Formação Aimbé, Grupo Guarinos, Goiás. Dissertação de Mestrado, Instituto de Geociências, Universidade de Brasília, 124 pg.

RESENDE, M.G. \& JOST, H. 1994. Redefinição da Formação Aimbé, greenstone belt de Guarinos, Goiás, e sua inteprétação pelaogeográfica e paleotectônica. SBG, Boletim Geoc. Centro-Oeste, 17(1/2):49-57

TASSINARI, C.C.G. \& MONTALVÃO, R.M.G. 1980. Estudo geocronológico do greenstone belt de Crixás. in: SBG, XXXI Congr. Brasileiro de Geologia, Camburiú, SC, Anais, 5:2752-2759

TAYLOR, S.R. \& MCLENNAN, S.M. 1985. The continental crust: its composition and evolution. Blackwell Sci. Publ., 312 pp.

THAUER, R.K. 1982. Nickel tetrapyrroles in methanogenic bactéria: structure, function and biosynthesis. Anaerobic Digest, 3:37-44

THEODORO, S.M.C.H. 1995. Ambientes de Sedimentação da Formação Ribeirão das Antas, Grupo Crixás, Goiás. Dissertação de Mestrado, Instituto de Geociências, Universidade de Brasília, 88 pgs.

THEODORO, S.M.C.H. \& JOST, H. 1996. The discovery of primary sedimentary structures in Archean marbles of the Crixás greenstone belt, Central Brazil. In: Symposium Archaean Terr. South Amer. Platform, Brasília, 1996, Extended Abstract, pp.: 41-42

VARGAS, M.C. 1992. Geologia dos granito-gnaisses dos terrenos granito-greenstone da região de Crixás, Guarinos, Pilar de Goiás e Hidrolina, Goiás. Instituto de Geociências, Universidfade de Brasília, Dissertação de Mestrado, 172 pg. (inédito)

WRONKIEWICZ, D.J. \& CONDIE, K.C. 1987. Geochemistry of Archaean shales from the Witwatersrand Supergroup, South África: source-area weathering and provenance. Geochim. et Cosmochem. Acta., 51:2401-2416

MANUSCRITO A904

Recebido em 15 de janeiro de 1997 Revisão dos autores em 4 de marco de 1997 Revisão aceita em 8 de março de 1997 